\title{
OSMOTIC ADAPTATION OF NUCLEUS PULPOSUS CELLS: THE ROLE OF AQUAPORIN 1, AQUAPORIN 4 AND TRANSIENT RECEPTOR POTENTIAL VANILLOID 4
}

\author{
J.W. Snuggs, R.A.D. Bunning and C.L. Le Maitre* \\ Biomolecular Sciences Research Centre, Sheffield Hallam University, Sheffield, UK
}

\begin{abstract}
The microenvironment of the nucleus pulposus is hyperosmotic and fluctuates diurnally due to mechanical loading. Changes in extracellular osmolality result in cell volume alterations, responsiveness to such changes is essential for cellular homeostasis. Aquaporins allow movement of water across cell membranes and control water permeability in response to osmotic gradients. Furthermore, transient receptor potential vanilloid 4 has been shown to sense osmotic and mechanical stimuli resulting in changes to intracellular $\mathrm{Ca}^{2+}$. It has been shown previously that aquaporin 1 and 4 expression decreases during disc degeneration. Here, the expression of transient receptor potential vanilloid 4 by human nucleus pulposus cells during disc degeneration, and the roles of aquaporin 1, 4 and transient receptor potential vanilloid 4 in regulating responses to osmotic gradients was investigated. Transient receptor potential vanilloid 4 was expressed by the majority of human nucleus pulposus cells and not affected by disc degeneration. Aquaporin 4 staining co-localised with primary cilia. Nucleus pulposus cells modulated their rate of volume change, water permeability and $\mathrm{Ca}^{2+}$ influx in response to extracellular osmolality. These responses were inhibited by chemical inhibition of aquaporin 4, transient receptor potential vanilloid 4, and to a lesser extent aquaporin 1; suggesting that both aquaporins and transient receptor potential vanilloid 4 play important roles in the fundamental adaptation of nucleus pulposus cells to their osmotic environment. Co-localisation with primary cilia indicates these proteins may function synergistically to achieve adaptation, which may be lost during disc degeneration, when aquaporin 1 and 4 expression is reduced.
\end{abstract}

Keywords: Aquaporin, TRPV4, nucleus pulposus, osmotic adaptation, water permeability.

*Address for correspondence: Professor Christine Le Maitre, Biomolecular Sciences Research Centre, Sheffield Hallam University, City Campus, Howard Street, Sheffield S1 1WB, UK.

Email: C.Lemaitre@shu.ac.uk

Copyright policy: This article is distributed in accordance with Creative Commons Attribution Licence (http://creativecommons.org/licenses/by-sa/4.0/).

\section{Introduction}

The local environment of the nucleus pulposus (NP) is hyperosmotic when compared to many other tissues (Ishihara et al., 1997). Yet, the osmolality never remains constant as loading applied onto the disc forces water and ions out of the tissue as proteoglycans are compressed (McMillan et al., 1996). Therefore, the intervertebral disc (IVD) and its environment undergo a diurnal cycle where NP cells must adapt to daily fluctuations in tissue osmolality and mechanical loading. The diurnal cycle of loading and consequential changes to the NP environment are important for regulating the correct function of NP cells (Ishihara et al., 1997; Neidlinger-Wilke et al., 2012; O'Connell et al., 2014; Wuertz et al., 2007). During degeneration, when proteoglycan content of the IVD is reduced, the osmolality and mechanical loading of the tissue is permanently altered, interfering with the usual diurnal cycle. The altered environment contributes to degenerative processes, during which cells lose their ability to adapt to osmotic and mechanical cues and start producing catabolic factors (Gilbert et al., 2010; Gilbert et al., 2011; Le Maitre et al., 2009; Sowa et al., 2012). The ability of cells to perceive and respond to their environment is essential for their correct function, yet the exact mechanisms NP cells employ to adapt to the osmotic and mechanical environment and how these are altered during degeneration, are not completely understood.

Changes in extracellular osmolality causes flux of water, which results in cell swelling or shrinkage, depending on the osmotic gradient. The ability of cells to regulate their volume is essential for the 
maintenance of cellular homeostasis. Aquaporins (AQPs) allow the bi-directional movement of water and other small solutes through the cell membrane and control the water permeability of cells in response to even very small osmotic gradients (Agre et al., 2002). AQP expression and function allows the control of water permeability, enabling fundamental functions of cells (Day et al., 2014; Galán-Cobo et al., 2016; Kitchen and Conner, 2015; Krane et al., 2001; Ozu et al., 2018; Tanaka and Koyama, 2011). NP cells express a wide number of AQPs (Gajghate et al., 2009; Johnson et al., 2015; Richardson et al., 2008; Snuggs et al., 2019). Experimentally, under hyperosmotic conditions mimicking the healthy environment of the disc, AQP2 expression is upregulated in NP cells, indicating AQP expression and function may be controlled by the osmotic environment within the disc (Gajghate et al., 2009). During IVD degeneration the expression of some AQPs, including AQP1 and 4, is decreased (Johnson et al., 2015; Snuggs et al., 2019), which may result from the decreased extracellular osmolality due to matrix degradation. If AQP function contributes to the adaptation of NP cells to their environment, the loss of AQP1 and 4 during degeneration could be detrimental as cells can no longer function correctly within the altered osmotic environment of the NP.

Cells have adapted complex mechanisms to sense and respond to environmental stimuli. A group of transmembrane proteins that play a key role in adaptation to the environment are transient receptor potential (TRP) channels. The TRP channel family enable cells to respond to environmental stimuli by altering intracellular $\mathrm{Ca}^{2+}$ concentration, which activates signal transduction pathways (Samanta et al., 2018). The transient receptor potential vanilloid (TRPV) subfamily (TRPV1-6) have diverse functions (Caterina et al., 1997). In particular, TRPV4 has been shown to play an important role in cellular response to osmotic and mechanical stress (Köhler et al., 2006; Liedtke et al., 2000; Nilius et al., 2001; Strotmann et al., 2000; Toft-Bertelsen et al., 2018). TRPV4 is expressed in a wide variety of tissues (Everaerts et al., 2010) and is activated by hypo-osmotic stimuli, when cell volume increases, enabling the influx of $\mathrm{Ca}^{2+}$. This leads to the activation of $\mathrm{Ca}^{2+}$-dependent $\mathrm{K}^{+}$channels (Arniges et al., 2004) and regulatory volume decrease (RVD) mechanisms (Liedtke and Friedman, 2003; Wu et al., 2007) after initial cell swelling. Cells can thus regulate the flux of osmolytes and balance external and intracellular osmotic pressure, to control the rate of cell swelling and adapt to hypo-osmotic environments.

However, there have been limited studies on TRPV4 expression and function in the IVD. It has been shown that exposing mouse mesenchymal stem cells to low magnitude compression enables their differentiation to an NP cell-like phenotype via a TRPV4-dependent pathway (Gan et al., 2018) and in bovine NP cells TRPV4 expression was upregulated by hypo-osmolality (Walter et al., 2016). The same study also showed limited preliminary data that suggested TRPV4 expression in human IVDs was decreased during degeneration (Walter et al., 2016). No studies to date, have identified how TRPV4 function potentially affects NP cell physiology in response to osmotic stimuli. TRPV4 has an established role in cartilage physiology, mediating mechanotransduction (O'Conor et al., 2014), and regulating RVD mechanisms following hypoosmotic stimuli (Lewis et al., 2011), indicating that TRPV4 contributes to healthy cartilage physiology. Indeed, mutations to TRPV4 have been shown to reduce channel activity and induce osteoarthritis (Lamandé et al., 2011) and deletion of TRPV4 in a mouse model leads to a lack of osmotically-driven $\mathrm{Ca}^{2+}$ influx and the onset of osteoarthritis (Clark et al., 2010). Therefore, TRPV4 may also be implicated in the adaptation of NP cells to their hyperosmotic environment and the overall health of the disc.

Interestingly, there is also evidence that the functions of AQPs and TRPV4 may be linked. The ability of many cell types to sense changes in extracellular osmolality and trigger RVD mechanisms may rely on AQPs and TRPV4 functioning in synergy. In rabbit cortical collecting duct cells, hypo-osmotic activation of TRPV4 and RVD mechanisms were reliant on AQP2 expression (Galizia et al., 2012). Similar activation of TRPV4 and RVD was reliant on AQP5 in mouse salivary gland cells (Liu et al., 2006) and AQP4 and TRPV4 have been shown to interact to control RVD in mouse retinal Müller cells (Jo et al., 2015). AQP4 has also been shown to co-localise with TRPV4 in mouse astrocytes and form a complex that controls the regulation of cell volume (Benfenati et al., 2011). Mola et al. (2016) identified that AQP1 and 4-influenced swelling was the main trigger for RVD and TRPV4 mediated calcium signalling in mouse astrocytes (Mola et al., 2016). This regulatory role suggests AQPs, along with TRPV4, contribute to many fundamental processes enabling cellular adaptations. This is in addition to the function of AQPs as passive water channels, which has been suggested as one of the many mechanisms that potentially enable NP cells to sense changes in their extracellular environment (Sadowska et al., 2018).

Other important mechanisms enabling cells to adapt to their osmotic environment involve the function of primary cilia. Primary cilia are microtubule-based cell surface organelles expressed by mammalian tissues (generally one per-cell), including the IVD (Donnelly et al., 2008). They can modulate signalling pathways in response to many extracellular stimuli including alterations in osmolality (Choi et al., 2019; Narita et al., 2010; Siroky et al., 2017) and mechanical stress (Corrigan et al., 2018; McGlashan et al., 2010) via specialised calcium signalling (Delling et al., 2013). Many TRP channel family members, including TRPV4, are localised to primary cilia (Corrigan et al., 2018; Kleene et al., 2019; Nauli et al., 2016; Pablo et al., 2017; Siroky et al., 2017), highlighting their role in cellular adaptation to such 
stimuli. Within the IVD, primary cilia are important for cell organisation and function (Li et al., 2020) and have been shown to modulate their length in response to osmolality (Choi et al., 2019). Therefore, if AQP1, 4 or TRPV4 are localised to primary cilia in NP cells, this could relate to a co-functionality regarding cellular adaptation to the extracellular environment.

As AQP1 and 4 are among the AQP isoforms that have a high water permeability (Kitchen et al., 2015; Yang and Verkman, 1997) their role in NP cells, and whether AQPs work in unison with TRPV4 is important to understand, especially as a decrease in AQP1 and 4 expression is observed during IVD degeneration (Johnson et al., 2015; Snuggs et al., 2019). This could result in a loss of NP cell adaptation to the IVD environment, when it becomes hypo-osmotic. In addition, potential co-localisation with primary cilia, which may enable adaptation to the fluctuating osmotic environment, is important to determine.

The working hypothesis was that human NP cells are able to adapt to their extracellular osmotic environment by rapidly altering the rate of volume and water permeability change, and that the functions of AQP1, 4 and TRPV4 enable these adaptations that are potentially lost during IVD degeneration. To determine the physiological roles of AQP1, AQP4 and TRPV4 in the IVD, this study investigated the expression of TRPV4 in native human NP tissue to determine if levels were altered during degeneration and the potential co-localisation of AQP4 (Benfenati et al., 2011), TRPV4 and primary cilia (Siroky et al., 2017). Furthermore, how human NP cells adapt to changes in extracellular osmolality and the potential involvement of $\mathrm{AQP} 1, \mathrm{AQP} 4$ and TRPV4 in regulating cell volume change and calcium influx was studied.

\section{Materials and Methods}

\section{Experimental design}

To investigate TRPV 4 expression, immunohistochemistry (IHC) was performed on non-degenerate and degenerate human NP tissue. Co-localisation of AQP4, TRPV4 and primary cilia was determined in human NP cells using confocal microscopy. These investigations were performed as the staining patterns of AQP4 reported previously (Snuggs et al., 2019), appeared similar to TRPV4 staining observed here. Furthermore, IHC for AQP4 and TRPV4 staining appeared to identify cilia structures. AQP1 staining patterns previously reported (Snuggs et al., 2019) did not show similar staining patterns and thus were not investigated in the current study.

To investigate how human NP cells respond to shifts in extracellular osmolality, cells were exposed to rapid physiological alterations to osmolality to mimic healthy and degenerate conditions and the fluxes seen during diurnal loading. A plate-reader based assay, utilising the self-quenching effects of calcein-AM in response to relative intracellular concentration, was used to determine the rate at which NP cells respond to extracellular osmolality changes by modulating their size (Fenton et al., 2010). To determine the actual change in cell volume to rapid changes in osmolality, flow cytometry and fluorescence microscopy methods were utilised. Measurements taken from both the rate of cell volume change and the actual cell volume change were used to determine the relative water permeability from equations outlined by Fenton et al. (2010). Due to the high water permeability of AQP1 and 4 and the proposed

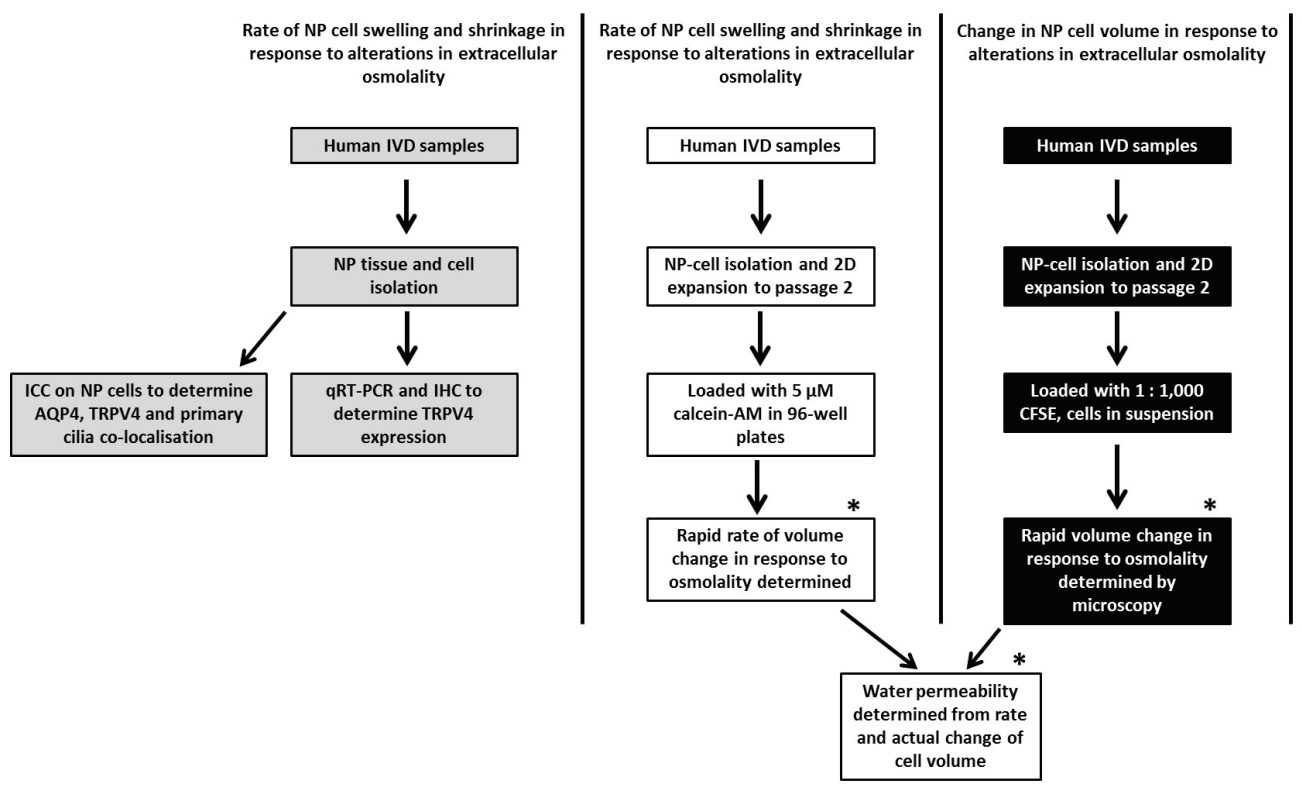

Rate of $\mathrm{Ca}^{2+}$ influx into NP cells in response to alterations in extracellular osmolality
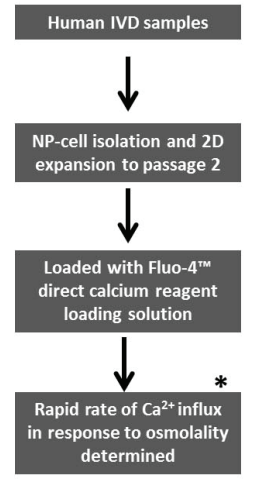

Fig. 1. Experimental design used in this study. 
roles of TRPV4 in RVD regulation, specific channel inhibition of AQP1, 4 and TRPV4 were utilised to determine their role during these processes. Calcium influx in response to altered osmolality, an important cellular adaptation response, was measured using Fluo-4 direct calcium assay. As AQP4 and TRPV4 co-localised in NP cells (indicating potential shared functions), specific inhibitors of both channels were used to investigate the effects of each channel on calcium influx in response to osmotic stimuli. NP cells were either treated with specific inhibitors to block channel function or left as uninhibited controls during all experiments. The experimental design is outlined in Fig. 1.

\section{Human tissue processing and grading}

Human IVD tissue was obtained from patients undergoing microdiscectomy surgery with informed consent of the patients (Sheffield Research Ethics Committee (09/H1308/70). IVD tissue was fixed in $10 \%(\mathrm{v} / \mathrm{v})$ neutral buffered formalin (Leica, Milton Keynes, UK), embedded into paraffin wax and $4 \mu \mathrm{m}$ sections were cut before being histologically graded using previously published methods (Le Maitre et al., 2007). IVD samples were separated into different groups depending on their grade of degeneration: non-degenerate (grade 0-4), moderately-degenerate (grade 4.1-6.9) and severely-degenerate (grade 7-12).

\section{NP-cell isolation and culture}

Human NP tissue was dissected and cells isolated using $2 \mathrm{mg} / \mathrm{mL}$ collagenase type I (Life Technologies, Paisley, UK) at $37^{\circ} \mathrm{C}$ for $4 \mathrm{~h}$, as described previously (Johnson et al., 2015; Snuggs et al., 2019). Following isolation human, NP cells were expanded using Dulbecco's Modified Eagle medium (DMEM, Gibco, Paisley, UK) supplemented with $10 \%(\mathrm{v} / \mathrm{v})$ foetal bovine serum, 10,000 U/mL penicillin, $10 \mathrm{mg} / \mathrm{mL}$ streptomycin (Gibco), $25 \mu \mathrm{g} / \mathrm{mL}$ amphotericin B (SigmaAldrich, Gillingham, UK), $2 \mathrm{mmol} / \mathrm{L}$ L-glutamine (Gibco) in monolayer up to passage 2.

\section{TRPV4 gene expression in native human NP tissue}

Directly following human NP cell isolation, RNA was extracted using TRIzol (Life Technologies) and cDNA synthesised as previously published (Johnson et al., 2015; Snuggs et al., 2019). The gene expression of TRPV4 in directly extracted human NP samples was identified using qRT-PCR on cDNA synthesised from non-degenerate $(n=14)$, moderately-degenerate $(n=17)$ and severely-degenerate $(n=32)$ human NP tissue (Table 1). Pre-designed Taqman primer/ probe mix for human TRPV4 gene (Hs01099348_m1, Life Technologies) was used and normalised to the average $C_{t}$ values of two housekeeping genes: GAPDH and 18s. Data were analysed using the $2^{-\Delta C t}$ method, where each sample was normalised to housekeeping genes (Livak and Schmittgen, 2001).

\section{TRPV4 protein expression in native human NP tissue}

The expression of TRPV4 protein in non-degenerate $(n=10)$, moderately-degenerate $(n=10)$ and severelydegenerate $(n=10)$ graded human NP tissue was assessed using IHC as described previously (Binch et al., 2020) (Table 1). Slides were de-waxed, rehydrated and endogenous peroxidases blocked before enzyme antigen retrieval $[0.01 \% \mathrm{w} / \mathrm{v} \alpha$-chymotrypsin (SigmaAldrich) in TBS (20 mmol/L Tris, $150 \mathrm{mmol} / \mathrm{L} \mathrm{NaCl}$, $\mathrm{pH} 7.5$ ) containing $0.1 \% \mathrm{w} / \mathrm{v} \mathrm{CaCl}_{2}$ for $30 \mathrm{~min}$ at $37^{\circ} \mathrm{C}$. Non-specific antibody binding was blocked in $1 \%(\mathrm{w} / \mathrm{v})$ bovine serum albumin in $25 \%(\mathrm{v} / \mathrm{v})$ goat serum (Abcam, Cambridge, UK) and $75 \%$ $(\mathrm{v} / \mathrm{v})$ tris-buffered saline (TBS) for $1 \mathrm{~h}$ at room temperature. Rabbit polyclonal primary antibody against TRPV4 (1 : 200, ab94868, Abcam) was incubated on slides overnight at $4{ }^{\circ} \mathrm{C}$. All antibodies were diluted in TBS containing $1 \%(\mathrm{w} / \mathrm{v})$ bovine serum albumin and IgG controls were used in the place of the primary antibody at an equal protein concentration. Slides were then incubated with goat anti-rabbit IgG (H\&L) (Biotin) secondary antibody (1 : 500, ab6720, Abcam) for 30 min. Antibody binding was detected by adding Elite ${ }^{\circledR} \mathrm{ABC}$ reagent (Vector Laboratories, Peterborough, UK) for $30 \mathrm{~min}$ at room temperature followed by addition of $0.08 \%$

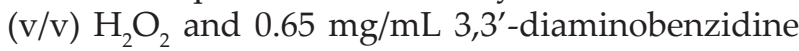
tetrahydrochloride (Sigma-Aldrich) in TBS for $20 \mathrm{~min}$ at room temperature. Nuclei were counterstained with Mayer's haematoxylin for $1 \mathrm{~min}$ before slides were dehydrated, cleared, and mounted using Pertex ${ }^{\circledR}$ (Leica). Slides were visualised using an Olympus BX60 microscope and images captured using CellSens software (Olympus, Southend-on-Sea, UK). Histologically distinct areas of NP tissue were identified before using a raster pattern to move across the tissue, counting all NP cells in each field of view (brown staining = positive, purple nuclei staining only = negative). A total of $200 \mathrm{NP}$ cells were counted for each human IVD tissue section and the percentage of positively stained cells was determined.

\section{TRPV4, AQP4 and primary cilia localisation in human NP cells}

Human NP cells were seeded into chamber slides at a density of $1 \times 10^{4}$ cells/well overnight. Cells were then fixed for 5 min using $4 \%(\mathrm{w} / \mathrm{v})$ paraformaldehyde, permeabilised for $5 \mathrm{~min}$ using $0.1 \%(\mathrm{v} / \mathrm{v})$ Triton X-100 (Sigma-Aldrich) and immunofluorescence protocols were performed as described previously (Snuggs et al., 2019). To determine potential colocalisation of AQP4/TRPV4 and $\beta$-tubulin/TRPV4, individual and dual immunostaining was performed by incubating fixed NP cells with mouse monoclonal antibody against AQP4 (1: 200, ab9512, Abcam) and rabbit polyclonal antibody against TRPV4 (1 : 200, ab94868, Abcam), or rabbit polyclonal antibody against $\beta$-tubulin [AA2] (Alexa Fluor ${ }^{\circledR}$ 647) $(1$ : 200, 
Table 1. Human patient and IVD sample details used in this study. Samples were obtained from microdiscectomy surgery or from post mortem with informed consent of the patients (Sheffield Research Ethics Committee (09/H1308/70)). Samples were separated by average grade of IVD degeneration. Nondegenerate (0-4), moderately degenerate (4.1-6.9) and severely-degenerate (7-12). Samples were used in experimental procedures to determine the native gene (RT-qPCR) and protein (IHC) expression of TRPV4 in human IVDs, or used in cellular studies to determine protein localisation and the effects of channel inhibition on cell volume, water permeability and calcium influx. The experimental procedures each sample was used in is marked by ' $X$ '.

\begin{tabular}{|c|c|c|c|c|c|c|c|}
\hline Patient & Source & Age & IVD level & Average grade & RT-qPCR & IHC & Cellular studies \\
\hline 1 & Surgical & 54 & L5/S1 & 5 & & & $\bar{X}$ \\
\hline 2 & Surgical & 49 & L5/S1 & 6 & & & $x$ \\
\hline 3 & Surgical & 56 & L4/L5 & 5.5 & & & $X$ \\
\hline 4 & Surgical & 42 & L4/L5 & 3 & $X$ & $x$ & \\
\hline 5 & Surgical & 40 & L5/S1 & 3.9 & $x$ & $x$ & \\
\hline 6 & Surgical & 45 & L5/S1 & 4 & $x$ & & \\
\hline 7 & Surgical & 20 & L4/L5 & 2 & $\mathrm{X}$ & $X$ & \\
\hline 8 & PM & 45 & $\mathrm{~L} 3 / \mathrm{L} 4$ & 1 & $x$ & & \\
\hline 9 & Surgical & 42 & L5/S1 & 2 & & $X$ & \\
\hline 10 & Surgical & 42 & $\mathrm{~L} 5 / \mathrm{S} 1$ & 3 & $x$ & & \\
\hline 11 & Surgical & 45 & L4/L5 & 2.6 & $x$ & & \\
\hline 12 & Surgical & 21 & L5/S1 & 4 & $x$ & $x$ & \\
\hline 13 & Surgical & 46 & L5/S1 & 3 & $X$ & $x$ & \\
\hline 14 & Surgical & 27 & L5/S1 & 4 & & $X$ & \\
\hline 15 & Surgical & 45 & L5/S1 & 4 & & $X$ & \\
\hline 16 & Surgical & 26 & L5/S1 & 4 & $x$ & & \\
\hline 17 & PM & 33 & L4/L5 & 2 & $X$ & & \\
\hline 18 & PM & 33 & L2/L3 & 4 & $x$ & $X$ & \\
\hline 19 & Surgical & 20 & L4/L5 & 3 & $x$ & $X$ & \\
\hline 20 & Surgical & 63 & C5/C6 & 4 & $x$ & & \\
\hline 21 & Surgical & 25 & L4/L5 & 4.8 & $X$ & & \\
\hline 22 & Surgical & 32 & L5/S1 & 5 & $x$ & & \\
\hline 23 & Surgical & 40 & L5/S1 & 5 & $x$ & & \\
\hline 24 & Surgical & 28 & L4/L5 & 6 & $x$ & $X$ & \\
\hline 25 & Surgical & 56 & L5 & 6 & $x$ & $x$ & \\
\hline 26 & Surgical & 47 & L4/L5 & 6 & $\mathrm{X}$ & $\mathrm{X}$ & \\
\hline 27 & Surgical & 56 & L5 & 6 & $x$ & & \\
\hline 28 & Surgical & 56 & L4/L5 & 5 & $x$ & & \\
\hline 29 & Surgical & 65 & $\mathrm{C} 3 / \mathrm{C} 5$ & 6 & & $X$ & \\
\hline 30 & Surgical & 45 & L5/S1 & 6.5 & & $X$ & \\
\hline 31 & Surgical & 37 & L4/L5 & 5 & $X$ & 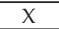 & \\
\hline 32 & Surgical & 47 & L5/S1 & 5 & $x$ & $x$ & \\
\hline 33 & Surgical & 32 & L5/S1 & 5.5 & & $x$ & \\
\hline 34 & Surgical & 18 & L4/L5 & 6 & $x$ & & \\
\hline 35 & Surgical & 46 & C5/C6 & 6 & $x$ & $X$ & \\
\hline 36 & Surgical & 33 & L4/L5 & 5 & $x$ & $x$ & \\
\hline 37 & PM & 33 & $\mathrm{~L} 3 / \mathrm{L} 4$ & 5 & $X$ & & \\
\hline 38 & Surgical & 54 & C6/C7 & 6 & $x$ & & \\
\hline 39 & Surgical & 35 & L5/S1 & 6 & $x$ & & \\
\hline 40 & Surgical & 42 & L5/S1 & 5 & $x$ & & \\
\hline 41 & Surgical & 33 & L5/S1 & 9 & $x$ & & \\
\hline 42 & Surgical & 48 & L4/L5 & 8 & $x$ & & \\
\hline 43 & Surgical & 26 & L5/S1 & 12 & $x$ & & \\
\hline 44 & Surgical & 33 & L5/S1 & 9 & $x$ & & \\
\hline 45 & PM & 74 & L2/L3 & 11 & & $X$ & \\
\hline 46 & Surgical & 26 & L5/S1 & 12 & $X$ & & \\
\hline 47 & Surgical & 36 & L5/S1 & 8 & $X$ & & \\
\hline 48 & Surgical & 38 & L5/S1 & 7 & $x$ & & \\
\hline 49 & Surgical & 44 & L5/S1 & 9 & $x$ & & \\
\hline 50 & Surgical & 28 & $\mathrm{~L} 5 / \mathrm{S} 1$ & 8 & $X$ & & \\
\hline 51 & Surgical & 43 & L4/L5 & 10 & $x$ & $x$ & \\
\hline 52 & Surgical & 62 & $\mathrm{~L} 3 / \mathrm{L} 4$ & 10 & $x$ & & \\
\hline 53 & Surgical & 40 & $\mathrm{~L} 3 / \mathrm{L} 4$ & 11 & $x$ & & \\
\hline 54 & Surgical & 85 & L2/L3 & 8 & & $x$ & \\
\hline 55 & Surgical & 40 & L5/S1 & 9 & $x$ & & \\
\hline 56 & Surgical & 38 & L5/S1 & 12 & $X$ & & \\
\hline 57 & Surgical & 66 & $\mathrm{~L} 5 / \mathrm{S} 1$ & 10 & $x$ & & \\
\hline 58 & Surgical & 46 & $\mathrm{~L} 5 / \mathrm{S} 1$ & 10 & $x$ & & \\
\hline 59 & Surgical & 65 & $\mathrm{~L} 3 / \mathrm{L} 4$ & 11 & $x$ & $x$ & \\
\hline 60 & Surgical & 45 & C5/C6 & 9.5 & & $x$ & \\
\hline 61 & Surgical & 38 & L4/L5 & 11 & $x$ & $x$ & \\
\hline 62 & Surgical & 70 & $\mathrm{C} 5 / \mathrm{C} 6$ & 8.5 & $X$ & & \\
\hline 63 & Surgical & 47 & L5/S1 & 8.5 & $X$ & & \\
\hline 64 & Surgical & 52 & L4/L5 & 11 & $X$ & $\mathrm{X}$ & \\
\hline 65 & Surgical & 39 & L4/L5 & 9 & $X$ & $x$ & \\
\hline 66 & Surgical & 33 & L4/L5 & 8 & $X$ & & \\
\hline 67 & Surgical & 29 & L5/S1 & 8 & $x$ & & \\
\hline 68 & Surgical & 35 & L4/L5 & 11 & $x$ & & \\
\hline 69 & Surgical & 38 & C6/C7 & 9 & $X$ & & \\
\hline 70 & Surgical & 42 & L4/L5 & 8 & $x$ & & \\
\hline 71 & Surgical & 38 & L5/S1 & 8 & $x$ & & \\
\hline 72 & Surgical & 54 & L5/S1 & 11 & $x$ & & \\
\hline 73 & Surgical & 36 & L5/S1 & 10 & $x$ & & \\
\hline 74 & Surgical & 44 & L5/S1 & 10 & $x$ & $x$ & \\
\hline 75 & Surgical & 54 & $\mathrm{~L} 5 / \mathrm{S} 1$ & 9 & $x$ & $x$ & \\
\hline
\end{tabular}


ab235759, Abcam) and TRPV4 (1 : 200, ab94868, Abcam), respectively. Primary cilia were stained using Acetyl- $\alpha$-tubulin (Lys40) (D20G3) $\mathrm{XP}^{\circledR}$ rabbit mAb (1 : 800, \#5335, Cell Signaling Technology, London, UK) alongside AQP4 primary antibody staining. During secondary antibody staining, fixed cells were incubated with goat anti-rabbit $\operatorname{IgG}(\mathrm{H}+\mathrm{L})$ cross-adsorbed, Alexa Fluor ${ }^{\circledR} 488$ (1 : 500, A-11008, Invitrogen, Paisley, UK,) (used for TRPV4), goat anti-mouse IgG $(\mathrm{H}+\mathrm{L})$ cross-adsorbed, Alexa Fluor ${ }^{\circledR}$ 633 (1 : 500, A-21050, Invitrogen) (used for AQP4 when dual staining for TRPV4), goat anti-rabbit IgG (H+L) cross-adsorbed, Alexa Fluor ${ }^{\circledR} 594$ (1 : 500, A32740, Invitrogen) (used for acetyl- $\alpha$-tubulin) and goat anti-mouse IgG $(\mathrm{H}+\mathrm{L})$ cross-adsorbed, Alexa Fluor $^{\circledR} 488$ (1 : 500, A32723, Invitrogen) (Used for AQP4 when dual staining for acetyl- $\alpha$-tubulin). Slides were mounted with diamond antifade mountant with 4',6-diamidino-2-phenylindole dihydrochloride (DAPI) (Life Technologies). Staining and colocalisation images were captured with an LSM 800 confocal microscope (Zeiss, Cambridge, UK) using Zen software (Zeiss).

\section{NP cell metabolic activity in the presence of inhibitors}

Human NP cells were seeded into 96-well plates (Corning, Flintshire, UK) at a density of $1 \times 10^{4}$ cells/well for $48 \mathrm{~h}$ prior to experiments. Media were aspirated, resazurin sodium salt (Sigma-Aldrich) stock solution ( $3 \mathrm{mg} / \mathrm{mL}$, prepared in DMEM) was diluted $1: 100$ (using DMEM) and was incubated on cells for $1 \mathrm{~h}$ at $37^{\circ} \mathrm{C} 5 \%(\mathrm{v} / \mathrm{v})$ before absorbance was read at excitation: $560 \mathrm{~nm}$, emission $590 \mathrm{~nm}$. Cells were exposed to no inhibitor [DMSO (dimethyl sulphoxide) vehicle control], $100 \mu \mathrm{mol} / \mathrm{L}$ AQP1 inhibitor (AQP1i) (TC AQP1 1, Tocris Bioscience, Abingdon, UK), $300 \mu \mathrm{mol} / \mathrm{L}$ AQP4 inhibitor (AQP4i) (TGN 020, Tocris Bioscience) or $4.8 \mu \mathrm{mol} / \mathrm{L}$ TRPV4 inhibitor (TRPV4i) (HC-067047, Sigma-Aldrich) for 1, 2 or $3 \mathrm{~h}$ to determine the effect of channel inhibition on metabolic activity. Fluorescence values were normalised to acellular controls. Metabolic activity was performed on cells from 3 patients in triplicate for each timepoint and treatment.

\section{Rate of human NP cell swelling and shrinkage}

Human NP cells were seeded into black-walled 96-well plates (Corning) at a density of $1 \times 10^{4}$ cells/ well for $48 \mathrm{~h}$ prior to experiments. Calcein-AM (C1430, Invitrogen) stock at $5 \mathrm{mmol} / \mathrm{L}$ in DMSO was produced. Cells were loaded with $5 \mu \mathrm{mol} / \mathrm{L}$ calceinAM ( $1: 1,000$ from stock) in standard culture media (325 mOsm $/ \mathrm{kg}$ ) for $90 \mathrm{~min}$ at $37{ }^{\circ} \mathrm{C}$. After calcein incubation, cells were washed twice with standard culture media, a final volume of $75 \mu \mathrm{L}$ standard culture medium was added per well and cells were allowed to equilibrate for at least $5 \mathrm{~min}$ at $37^{\circ} \mathrm{C}$. Prior to experiments, protocols to measure the rapid rate of change in calcein fluorescence within cells treated with altered osmolality media were set up on a
CLARIOstar ${ }^{\circledR}$ plate reader (BMG Labtech, Aylesbury, UK). This utilised the well mode to detect fluorescent intensity, with a preset of calcein optical settings (ex. 483-14, em. 530-30). Two kinetic windows were setup: a baseline reading of $5 \mathrm{~s}$ (time -5 to $0 \mathrm{~s}$ ) at $50 \mathrm{~ms}$ intervals, followed by injection (at time $0 \mathrm{~s}$ ) of $75 \mu \mathrm{L}$ osmotically altered media and a final kinetic window reading for $45 \mathrm{~s}(0-45 \mathrm{~s})$ at $50 \mathrm{~ms}$ intervals (total of 1,000 intervals). The protocol temperature was set to $37{ }^{\circ} \mathrm{C}$ and the plate reader injector and tubing was primed with an appropriate amount of treatment media prior to experiments. Once injected into each well (containing 75 L 325 mOsm/kg DMEM), treatment media rapidly altered the final osmolality to $225,325,425$ or $525 \mathrm{mOsm} / \mathrm{kg}$. For a final osmolality of $225 \mathrm{mOsm} / \mathrm{kg}$, media containing $38.5 \%$ (v/v) $\mathrm{dH}_{2} \mathrm{O}$ (125 mOsm/kg) was injected into each well. For a final osmolality of $325 \mathrm{mOsm} / \mathrm{kg}$, standard DMEM was injected into each well (no change in osmolality, control). For a final osmolality of $425 \mathrm{mOsm} / \mathrm{kg}$, media containing $200 \mathrm{mmol} / \mathrm{L}$ sucrose ( $525 \mathrm{mOsm} / \mathrm{kg}$ ) was injected into each well. For a final osmolality of $525 \mathrm{mOsm} / \mathrm{kg}$, media containing $400 \mathrm{mmol} / \mathrm{L}$ sucrose (725 mOsm $/ \mathrm{kg}$ ) was injected into each well. The osmolality of all solutions was confirmed by freezing point osmometry (Advanced ${ }^{\circledR}$ Model 3320 microosmometer, Advanced Instruments, Horsham, UK).

Plates were loaded into the plate reader and protocols were performed on NP cells from 3 patients in triplicate to determine the rate of human NP cell swelling and shrinkage in response to physiological alterations in extracellular osmolality. Experiments were performed after $1 \mathrm{~h}$ incubation of NP cells (already seeded into 96-well plates at $1 \times 10^{4}$ cells/ well) with no inhibitor (DMSO vehicle control), $100 \mu \mathrm{mol} / \mathrm{L}$ AQP1 inhibitor (AQP1i) (TC AQP1 1, Tocris Bioscience), $300 \mu \mathrm{mol} / \mathrm{L} \mathrm{AQP4} \mathrm{inhibitor}$ (AQP4i) (TGN 020, Tocris Bioscience) or $4.8 \mu \mathrm{mol} / \mathrm{L}$ TRPV4 inhibitor (TRPV4i) (HC-067047, SigmaAldrich) to determine the function of these channels on the rate of NP cell swelling and shrinkage. During inhibition experiments, all washes and treatment injections were performed with media containing $100 \mu \mathrm{mol} / \mathrm{L}$ AQP1i, $300 \mu \mathrm{mol} / \mathrm{L}$ AQP4i or $4.8 \mu \mathrm{mol} / \mathrm{L}$ TRPV4i when appropriate. Relative fluorescence of calcein $\left(\mathrm{F}_{1} / \mathrm{F}_{0}\right)$ over time $(\mathrm{s})$ curves were plotted and the rate of the change in $\mathrm{F}_{1} / \mathrm{F}_{0}$ was determined by fitting plateau followed by one phase association/ decay nonlinear regression analysis to curves using GraphPad Prism v7.03 software.

\section{Cell size determination}

Human NP cells (from 3 individual patients in triplicate) were trypsinised and resuspended in standard culture media at a density of $2 \times 10^{5}$ cells/ $\mathrm{mL}$. Live cells were labelled with CFSE - Cell Labelling Kit (1 : 1,000, ab113853, Abcam) for $10 \mathrm{~min}$ at RT protected from light and washed before being resuspended in $1 \mathrm{~mL}$ standard culture media. No inhibitor (DMSO vehicle control), AQP1, AQP4 or TRPV4 inhibitors were added as above. An equivalent 
amount $(1 \mathrm{~mL})$ of altered osmolality treatment media was added to cells for $\sim 30 \mathrm{~s}$ (time taken for calcein $\mathrm{F}_{1} / \mathrm{F}_{0}$ curves to plateau) before forward scatter (FSC) (proportional to cell size) was determined on 10,000 events using a FACSCalibur ${ }^{\mathrm{TM}}$ flow cytometer (BD Biosciences, Wokingham, UK) and CellQuest ${ }^{\mathrm{TM}}$ Pro v5.2.1 software (BD Biosciences). Furthermore, to determine actual cell size after 30 s treatment, cells at a density of $2 \times 10^{5}$ cells $/ \mathrm{mL}$ were added to Countess ${ }^{\mathrm{TM}}$ cell counting chamber slides (Invitrogen) and images of live [Carboxyfluorescein succinimidyl ester (CFSE) stained], suspended NP cells were captured using a BX60 fluorescence microscope (Olympus) using cellSens software (Olympus). The area of at least 200 cells/repeat from 2D images was determined using ImageJ (Schneider et al., 2012). Cells that had an aspect ratio of $\geq 1.5$ and an area of $\leq 100$ pixels were excluded to remove doublets/clumps of cells and cell debris. Size calculations of cells in suspension relied on the presumption that all suspended cells used for the analysis of 2D and 3D cell size had spherical morphology. Cell size was calculated from a series of equations, firstly to determine the radius of cells from 2D area measurements (Equation 1).

$$
r=\sqrt{\frac{A}{\pi}}
$$

Equation 1. Radius of a circle. Where $r=$ radius, $A=$ area, $\pi=$ pi.

Once the average radius of cells was determined, this was used to determine the average cell surface area (Equation 2) and average cell volume (Equation 3) for each repeat experiment.

$$
A=4 \pi r^{2}
$$

Equation 2. Surface area of a sphere. Where $A=$ surface area, $\pi=$ pi, $r=$ radius.

$$
V=\frac{4}{3} \pi r^{3}
$$

Equation 3. Volume of a sphere. Where $V=$ volume, $\pi=$ pi, $r=$ radius.

Both cell surface area and cell volume measurements, along with the rate of change in $\mathrm{F}_{1} / \mathrm{F}_{0}$ over time, were used to determine the water permeability of human NP cells in response to altered extracellular osmolality. All cell size determination experiments were performed after $1 \mathrm{~h}$ incubation of NP cells with No inhibitor (DMSO vehicle control), AQP1i (AQP1i) (100 $\mu \mathrm{mol} / \mathrm{L}$ TC AQP1 1, Tocris Bioscience), AQP4i (300 $\mu \mathrm{mol} / \mathrm{L}$ TGN 020, Tocris Bioscience) or TRPV4i (4.8 $\mu \mathrm{mol} / \mathrm{L}$ HC-067047, Sigma-Aldrich), which were also added to each wash, resuspension and CFSE incubation steps throughout the experimental procedure.

\section{Water permeability determination}

Using values calculated from the rate of NP cell swelling and shrinkage and NP cell size determination, the water permeability of human NP cells in response to alterations in extracellular osmolality and the potential involvement of AQP1, 4 and TRPV4, was determined using Equation 4.

$$
P f=\frac{K \times\left[V 0-V \min ^{2}\right]}{A \times \Delta \pi \times V w}
$$

Equation 4. Water permeability. Where $P f=$ water permeability, $K=$ rate constant for one phase decay/ association, $V 0=$ starting cell volume, $V \min ^{2}=$ cell volume after treatment, $A=$ cell surface area, $\Delta \pi=$ applied osmotic gradient, $V w=$ partial molar volume of water $\left(1.8 \times 10^{-5} \mathrm{~m}^{3} / \mathrm{mol}\right)$. As [V0 $\left.-\mathrm{Vmin}^{2}\right]$ reflects the total cell volume change in response to the change in extracellular osmolality, $K \times\left[V 0-\mathrm{Vmin}^{2}\right]$ describes the theoretical fraction of total volume change per one $x$-axis unit change $(50 \mathrm{~ms})$ at the initial rate of volume change (Fenton et al., 2010).

The average $P f$ of human NP cells, for each patient, was calculated in response to physiological changes in osmolality ( $325 \mathrm{mOsm} / \mathrm{kg} \rightarrow 225,425$ or $525 \mathrm{mOsm} /$ $\mathrm{kg}$ ) with or without AQP1i, AQP4i and TRPV4i. (Note it was not possible to calculate $\mathrm{P} f$ for $325 \mathrm{mOsm} / \mathrm{kg}$ as this is the starting media concentration). All $P f$ values were normalised to the average $P f$ of controls in the absence of inhibitors, to determine the effect of AQP1i, AQP4i and TRPV4i on the Pf of human NP cells at each extracellular osmolality change.

\section{Fluo-4 Direct ${ }^{\mathrm{TM}}$ calcium influx assay}

Calcium influx into human NP cells in response to extracellular osmolality alterations was measured using Fluo-4 Direct ${ }^{\mathrm{TM}}$ calcium assay kit (F10471, Invitrogen) as per the manufacturer's guidelines. Human NP cells were seeded into black-walled 96well plates (Corning) at a density of $1 \times 10^{4}$ cells/well for $48 \mathrm{~h}$ prior to experiments. Fluo- 4 Direct $^{\mathrm{TM}}(2 \times)$ calcium reagent loading solution (Invitrogen) was prepared following the manufacturer's guidelines: $10 \mathrm{~mL}$ Fluo-4 Direct ${ }^{\mathrm{TM}}$ calcium assay buffer was added to one bottle of Fluo- 4 Direct ${ }^{\mathrm{TM}}$ calcium reagent (component A). Media was aspirated from cells and an equal volume of Fluo- 4 Direct $^{\mathrm{TM}}(2 \times)$ calcium reagent loading solution $(37.5 \mu \mathrm{L})$ and standard culture media $(37.5 \mu \mathrm{L})$ was added to cells, for a total volume of $75 \mu \mathrm{L}$ per well. Plates were incubated for $1 \mathrm{~h}$ at $37^{\circ} \mathrm{C}$ protected from light. Following incubation, plates were ready for experimental use without removing Fluo-4 Direct ${ }^{\mathrm{TM}}(2 \times)$ calcium reagent loading solution and standard culture media from wells. Calcium influx into human NP cells in response to physiological alterations of extracellular osmolality (325 mOsm $/ \mathrm{kg} \rightarrow 225,325,425$ or $525 \mathrm{mOsm} / \mathrm{kg}$ final osmolalities) was performed on a CLARIOstar plate reader (BMG Labtech) following the same protocol outlined above (Rate of human NP cell swelling and 
shrinkage), with optic settings changed to excitation at $494 \mathrm{~nm}$ and emission at $516 \mathrm{~nm}$. Treatment media as described above (Rate of human NP cell swelling and shrinkage) was injected into wells after the first kinetic window ( -5 to $0 \mathrm{~s}$ ). As AQP4 and TRPV4 were found to co-localise, suggesting combined functions, experiments were performed after $1 \mathrm{~h}$ incubation of cells with either no inhibitor (DMSO vehicle control), AQP4i (300 $\mu \mathrm{mol} / \mathrm{L}$ TGN 020, Tocris)

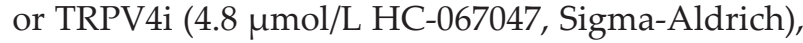
simultaneously added to cells with Fluo-4 Direct ${ }^{\mathrm{TM}}$ $(2 \times)$ calcium reagent loading solution and media. During AQP4i and TRPV4i experiments, inhibitors were also added to treatment media prior to injection.

\section{Statistical analysis}

TRPV4 protein expression in human NP tissue (assessed by IHC) was found to be non-parametric; therefore, Kruskall-Wallis with Dwass-SteelCritchlow-Fligner post hoc analysis test was used to identify significant differences between expression across grades of degeneration. The rate of cell swelling/ shrinkage (determined by calcein fluorescence) was investigated in triplicate in human NP cells from 3 patients. Data were non-parametric and to determine significance between paired samples from the same patient across 4 treatment groups (CTR, AQP1i, AQP4i and TRPV4i), the Friedman test was used with Conover post hoc analysis. Cell volume data was non-parametric; therefore, Kruskall-Wallis with Dwass-Steel-Critchlow-Fligner post hoc analysis test was used to identify significant differences in cell volume, at a fixed osmolality, when comparing treatment groups (CTR, AQP1i, AQP4i and TRPV4i). The Friedman test was used to determine significance between the geometric mean of the FSC, and the $P f$, from paired patient samples when comparing treatment groups (CTR, AQP1i, AQP4i and TRPV4i), at a fixed osmolality. $\mathrm{Ca}^{2+}$ influx data was nonparametric; therefore, Kruskall-Wallis with DwassSteel-Critchlow-Fligner post hoc analysis test was used to identify significant differences in the max-min $\mathrm{F}_{1} /$ $\mathrm{F}_{0}$ and time taken to reach maximum $\mathrm{F}_{1} / \mathrm{F}_{0}$ in NP cells treated with different osmolalities, or inhibitors (CTR, AQP4i and TRPV4i) at $225 \mathrm{mOsm} / \mathrm{kg}$.

\section{Results}

\section{Expression of TRPV4 within native human NP tissue}

TRPV4 was expressed at both gene and protein level within native human NP tissue (Fig. 2a,b). The relative gene expression of TRPV4 did not change significantly during IVD degeneration (Fig. 2a). The majority of NP cells expressed TRPV4 protein in native tissue; however, immunopositivity was unaffected by IVD degeneration (Fig. 2b-e). TRPV4 was also still expressed by NP cells extracted from human IVD tissue at passage 2 (Fig. 3). Within 2D cultured human NP cells TRPV4 was found to co- localise with AQP4 (Fig. 3a-c) and $\beta$-tubulin (Fig. $3 d-f)$, potentially suggesting related functions shared between these transmembrane channel proteins. AQP4 staining also co-localised with primary cilia, indicated by acetylated tubulin staining (Fig. 3g-i).

\section{Rate of NP cell swelling and shrinkage in response to extracellular osmolality}

Relative fluorescence $\left(\mathrm{F}_{1} / \mathrm{F}_{0}: \mathrm{F}_{1}=\right.$ fluorescence at time $\mathrm{n} / \mathrm{F}_{0}=$ fluorescence at baseline) of intracellular calcein in human NP cells is linearly correlated with extracellular osmolality (as osmolality decreases, calcein $\mathrm{F}_{1} / \mathrm{F}_{0}$ increases) (Fig. 4a), whereas actual cell volume and extracellular osmolality are not linearly correlated (Fig. 4b). Therefore, cell volume cannot be directly determined from calcein $\mathrm{F}_{1} / \mathrm{F}_{0}$; actual cell volume and the rate of cell volume change in response to extracellular osmolality must be measured separately. The metabolic activity of NP cells increased over time (Fig. 4c). After $2 \mathrm{~h}$ and $3 \mathrm{~h}$ incubation with DMSO (vehicle control), AQP1i, AQP4i and TRPV4i, the metabolic activity of human NP cells was significantly increased compared to $1 \mathrm{~h}$ incubation ( $p=<0.0001$ ) (Fig. 4c). There was no significant decrease in the metabolic activity of NP cells incubated with AQP1i, AQP4i and TRPV4i when compared to DMSO control at any timepoint (Fig. 4c), indicating no adverse effects of any treatment on cell growth or viability. Therefore, any experimental observations can be attributed to channel inhibition, not alterations to cell metabolic activity and viability.

$\mathrm{F}_{1} / \mathrm{F}_{0}$ of intracellular calcein was altered, in realtime, when no-inhibition DMSO control NP cells (CTR) were exposed to altered extracellular osmolality $(225,425$ and $525 \mathrm{mOsm} / \mathrm{kg})$, after $5 \mathrm{~s}$ baseline readings in standard culture media $(325 \mathrm{mOsm} / \mathrm{kg})$ (Fig. 5a). When control medium (325 mOsm/kg) was added after baseline, the $\mathrm{F}_{1} / \mathrm{F}_{0}$ was unchanged (Fig. 5a). Incubation with AQP4i (300 $\mu \mathrm{mol} / \mathrm{L}, \mathrm{TGN} 020)$ or TRPV4i (4.8 $\mu \mathrm{mol} / \mathrm{L}, \mathrm{HC}-067047)$ altered the real-time change in intracellular calcein $\mathrm{F}_{1} / \mathrm{F}_{0}$ when NP cells were exposed to $225 \mathrm{mOsm} / \mathrm{kg}$ (Fig. 5b), $425 \mathrm{mOsm} /$ $\mathrm{kg}$ (Fig. 5d) and $525 \mathrm{mOsm} / \mathrm{kg}$ (Fig. 5f) treatments. The rate of change in fluorescence $\left(\mathrm{K} \Delta \mathrm{F}_{1} / \mathrm{F}_{0}\right)$ at $225 \mathrm{mOsm} / \mathrm{kg}$ treatment was significantly reduced in AQP4i $(p=0.0022)$ and TRPV4i $(p=0.0183)$ treated NP cells when compared to no-inhibition control NP cells (CTR) (Fig. 5c). At $425 \mathrm{mOsm} / \mathrm{kg}$ treatment $\mathrm{K} \Delta \mathrm{F}_{1} /$ $\mathrm{F}_{0}$ was significantly decreased in AQP4i $(p=0.0095)$ and TRPV4i ( $p=0.0047)$ compared to CTR (Fig. 5e). At $525 \mathrm{mOsm} / \mathrm{kg}$ treatment $\mathrm{K} \Delta \mathrm{F}_{1} / \mathrm{F}_{0}$ was significantly decreased in TRPV4i ( $p=0.0023)$ compared to CTR (Fig. 5g). AQP1i treatment had no significant effect on the change in $\mathrm{F}_{1} / \mathrm{F}_{0}$ at any osmolality but followed a similar trend to AQP4i treatment (Fig. 5). When $\mathrm{NP}$ cells were exposed to $325 \mathrm{mOsm} / \mathrm{kg}$ (identical to media osmolality prior to exposure) no change in $\mathrm{F}_{1} / \mathrm{F}_{0}$ was observed in CTR, AQP1i, AQP4i or TRPV4i treated cells, therefore no $\mathrm{K} \Delta \mathrm{F}_{1} / \mathrm{F}_{0}$ values could be determined (data not shown). 
Change in NP cell volume in response to extracellular osmolality alterations

The observed increase in volume of no-inhibition control (CTR) NP cells exposed to $225 \mathrm{mOsm} / \mathrm{kg}$ was significantly reduced in human NP cells treated with AQP1i $(p<0.0001)$, AQP4i $(p=0.0154)$ and TRPV4i $(p<0.0001)$, when exposed to $225 \mathrm{mOsm} /$ $\mathrm{kg}$ (Fig. 6a). The volume NP cells when exposed to $325 \mathrm{mOsm} / \mathrm{kg}$ (starting osmolality of media) was unaltered across all treatment groups (Fig. 6b). The volume of AQP1i ( $p=0.0006)$, AQP4i $(p=0.034)$ and TRPV4i ( $p=0.0005)$ treated human NP cells exposed to $425 \mathrm{mOsm} / \mathrm{kg}$ was significantly reduced, when compared to no-inhibition control (CTR) NP cells (Fig. 6c). Only TRPV4i significantly decreased NP cell volume at $525 \mathrm{mOsm} / \mathrm{kg}$ when compared to noinhibition control (CTR) $(p=0.0069)$ (Fig. 6d). Cell volume results were confirmed using flow cytometry forward scatter measurements (data not shown).
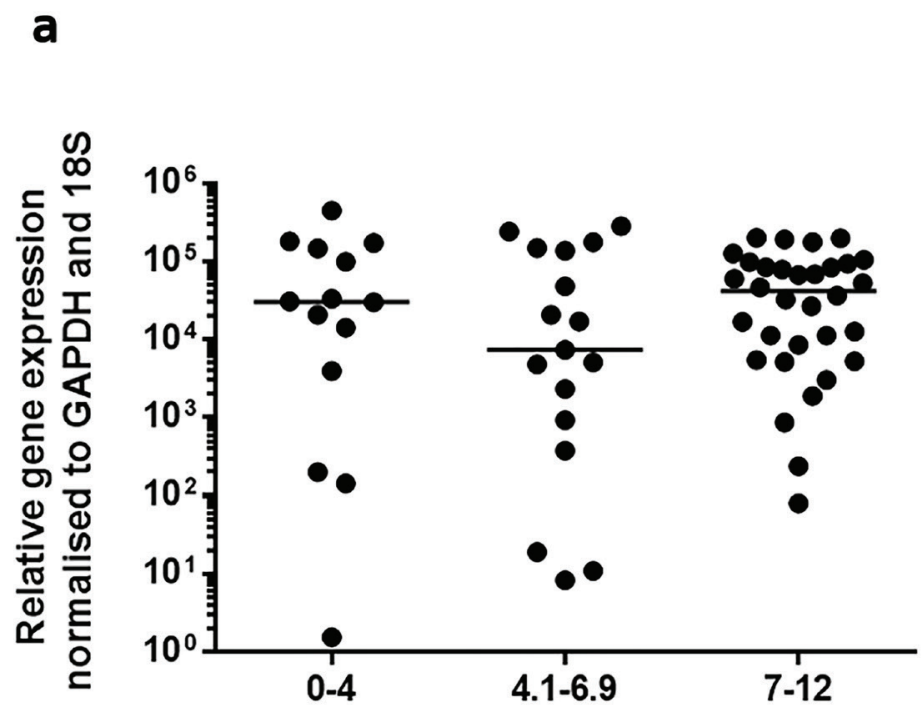

Histological grade of degeneration
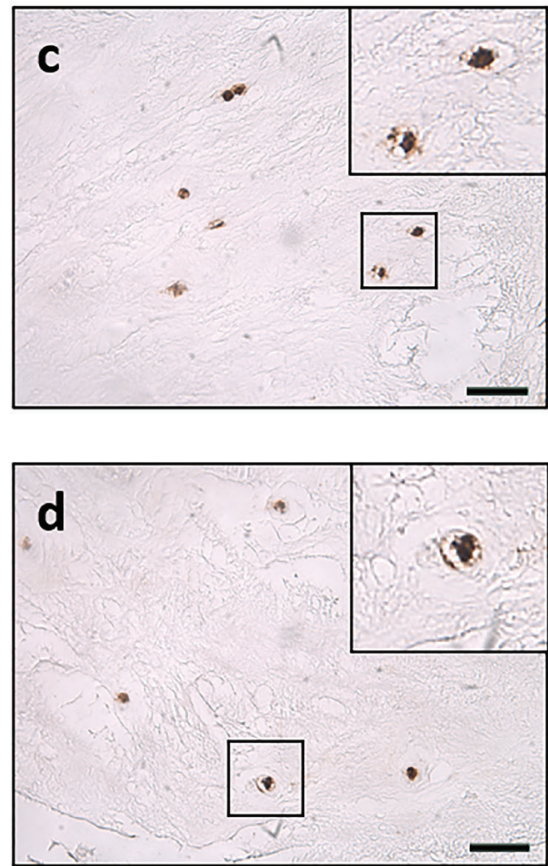

b

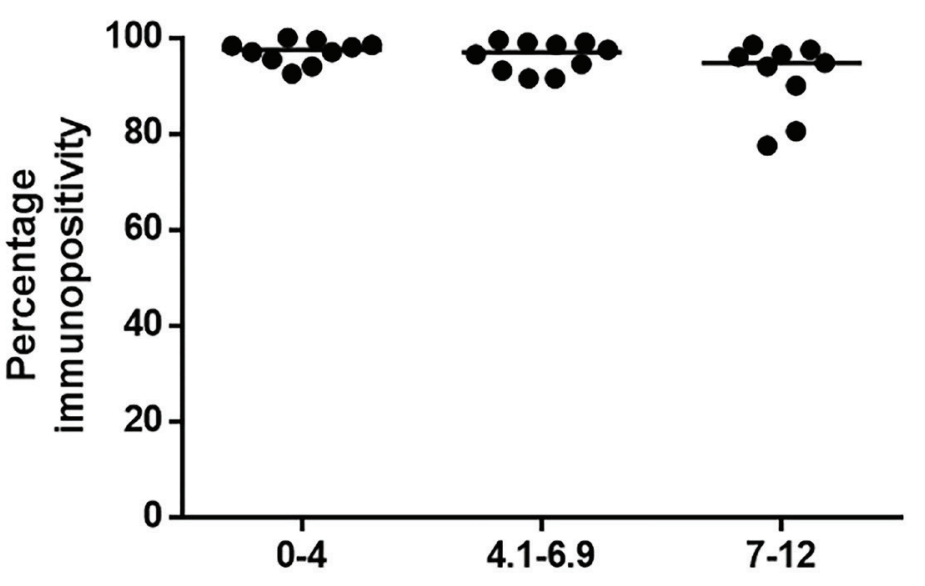

Histological grade of degeneration
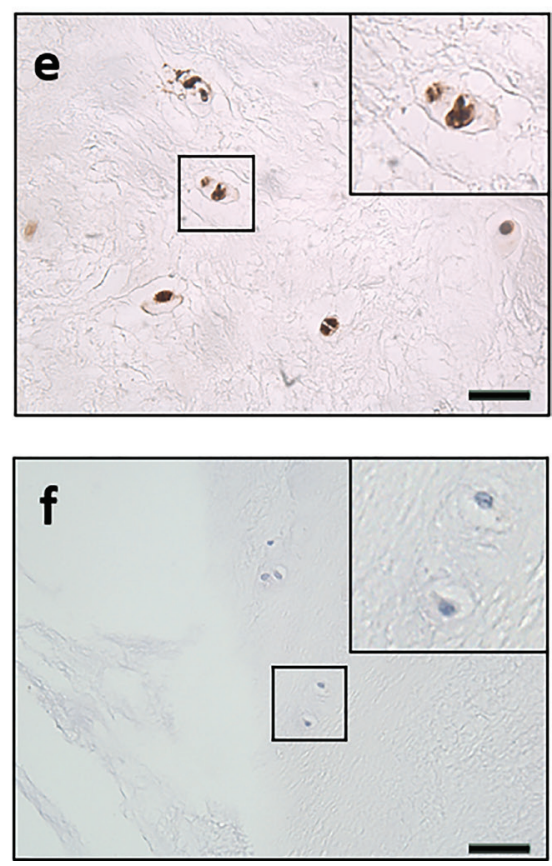

Fig. 2. TRPV4 expression in native human NP tissue. (a) relative TRPV4 gene expression in non-degenerate (grade 0-4), moderately-degenerate (grade 4.1-6.9) and severely-degenerate (grade 7-12) native human NP tissue. (b) Immunohistochemistry determining the percentage of native human NP cells that express TRPV4 protein in (c) non-degenerate (grade 0-4), (d) moderately-degenerate (grade 4.1- 6.9) and (e) severelydegenerate (grade 7-12) native human NP tissue. Brown cellular staining indicates cells expressing TRPV4. (f) IgG control image. Cells counterstained with Mayer's haematoxylin (blue). Scale bar (c-e) $50 \mu \mathrm{m}$. 
Effect of AQP1, AQP4 and TRPV4 inhibition on the water permeability of human NP cells

The normalised $\mathrm{P} f$ of human NP cells was significantly reduced with AQP4i $(p=0.0013)$ and TRPV4i $(p=0.0006)$ at $225 \mathrm{mOsm} / \mathrm{kg}$, when compared with CTR cells at $225 \mathrm{mOsm} / \mathrm{kg}$ (Fig. 7a). At $425 \mathrm{mOsm} /$ $\mathrm{kg}$, AQP4i $(p=0.0008)$ and TRPV4i $(p=0.0011)$ significantly reduced the normalised $\mathrm{P} f$ of human NP cells when compared to CTR cells (Fig. 7b). At $525 \mathrm{mOsm} / \mathrm{kg}$ treatment, only TRPV4i significantly $(p=0.0053)$ reduced the normalised Pf of human NP cells when compared to CTR cells (Fig. 7c). AQP1i treatment had no significant effect on relative water permeability at any osmolality but followed a similar trend to AQP4i treatment. Changes in extracellular osmolality $(225,425$ and $525 \mathrm{mOsm} / \mathrm{kg}$ ) did not significantly alter the Pf of CTR NP cells (data not shown). To determine $\mathrm{P} f$, values for both $\mathrm{K} \Delta \mathrm{F}_{1} / \mathrm{F}_{0}$ and actual cell volume are required (Equation 4$)$. When cells (CTR, AQP1i, AQP4i or TRPV4i) were exposed to $325 \mathrm{mOsm} / \mathrm{kg}$ cell volume was unchanged and no $\mathrm{K} \Delta \mathrm{F}_{1} / \mathrm{F}_{0}$ values could be determined (data not shown). Therefore, the water permeability of NP cells at $325 \mathrm{mOsm} / \mathrm{kg}$ could not be determined.

\section{Human NP cell calcium influx in response to} altered extracellular osmolality

The $\mathrm{F}_{1} / \mathrm{F}_{0}$ of intracellular Fluo- 4 direct, relative to $\mathrm{i}\left[\mathrm{Ca}^{2+}\right]$, was altered in real-time, when NP cells were exposed to altered extracellular osmolality $(225,325$, 425 and $525 \mathrm{mOsm} / \mathrm{kg}$ ), after $5 \mathrm{~s}$ baseline readings in standard culture media (325 mOsm/kg) (Fig. 8a). The max-min $\mathrm{F}_{1} / \mathrm{F}_{0}$ of intracellular Fluo- 4 direct was significantly increased in $225 \mathrm{mOsm} / \mathrm{kg}$ treated NP cells, compared to all other osmotic treatments $(p=0.002)$ and significantly higher in $325(p=0.0354)$ and $425 \mathrm{mOsm} / \mathrm{kg}(p=0.04)$ treatment compared to $525 \mathrm{mOsm} / \mathrm{kg}$ (Fig. 8b). The time taken to reach max $\mathrm{F}_{1} / \mathrm{F}_{0}$ in human NP cells was significantly shorter when exposed to $225 \mathrm{mOsm} / \mathrm{kg}$ media compared to all other treatments $(p=0.0025)$ (Fig. 8 b).
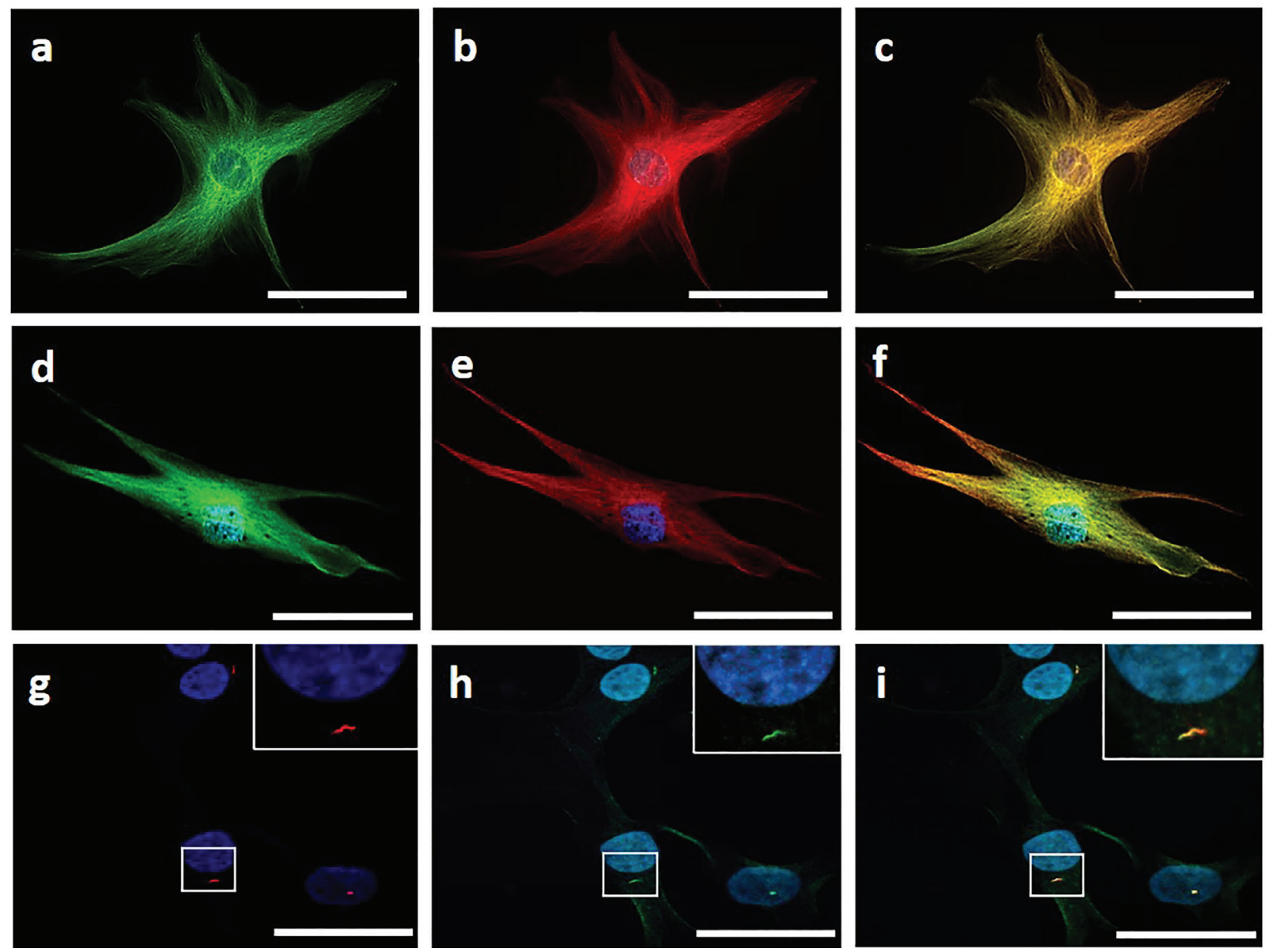

Fig. 3. Localisation of TRPV4, AQP4 and primary cilia in human NP cells. (a-c) Co-localisation of (a) TRPV4 (green) and (b) AQP4 (red), (c) shows the merged composite of image $\mathbf{a}$ and $\mathbf{b}$ showing co-localisation (yellow). (d-f) Co-localisation of (d) TRPV4 (green) and (e) $\beta$-tubulin (red), (f) shows the merged composite of image a and b showing co-localisation (yellow). (g-i) Co-localisation of primary cilia and AQP4. (g) acetylated tubulin staining (red) indicating the localisation of primary cilia. (h) AQP4 staining (green). (i) Merged image identifying co-localisation of acetylated tubulin and AQP4 (yellow). Inset images show higher magnification indicating localisation. All human NP cells counterstained with DAPI (blue). Images captured on an LSM 800 confocal microscope (Zeiss) using Zen software (Zeiss). Scale bars $20 \mu \mathrm{m}$. 
Effect of AQP4 and TRPV4 inhibition on hypoosmotic $\mathrm{Ca}^{2+}$ influx in human NP cells

The $\mathrm{F}_{1} / \mathrm{F}_{0}$ of intracellular Fluo-4 direct, relative to ${ }_{\mathrm{i}}\left[\mathrm{Ca}^{2+}\right]$, was altered in real-time, when NP cells were exposed to $225 \mathrm{mOsm} / \mathrm{kg}$ extracellular osmolality after AQP4i, TRPV4i or CTR treatment, and $5 \mathrm{~s}$ baseline readings in standard culture media (325 mOsm/kg) (Fig. 8d). The max-min $\mathrm{F}_{1} / \mathrm{F}_{0}$ of intracellular Fluo-4 direct was significantly increased in $225 \mathrm{mOsm} / \mathrm{kg}$ control NP cells, compared to AQP4i $(p=0.0024)$ and TRPV4i $(p=0.0023)$ treated NP cells (at $225 \mathrm{mOsm} / \mathrm{kg}$ ); both treatments reduced max-min $\mathrm{F}_{1} / \mathrm{F}_{0}$ values to a level comparable with $325 \mathrm{mOsm} / \mathrm{kg}$ control treatment (Fig. 8e). The time taken to reach maximum $\mathrm{F}_{1} / \mathrm{F}_{0}$ of intracellular Fluo-4 direct in AQP4i treated NP cells (at $225 \mathrm{mOsm} / \mathrm{kg}$ ) was significantly increased when compared to $225 \mathrm{mOsm} / \mathrm{kg}$ control and TRPV4i treated NP cells $(p \leq 0.003)$ (Fig. 8f). Only inhibition of AQP4 and TRPV4 was investigated here because both channels appear to co-localise in human NP cells, suggesting combined function, whereas AQP1 does not (Snuggs et al., 2019). Also, AQP4 and TRPV4 have been shown to co-localise and perform combined functions within other cell types previously (Benfenati et al., 2011; Mola et al., 2016), therefore, this was investigated here.

a

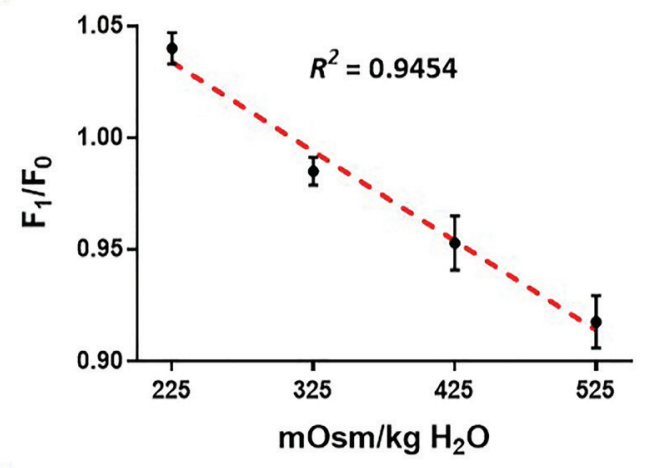

b

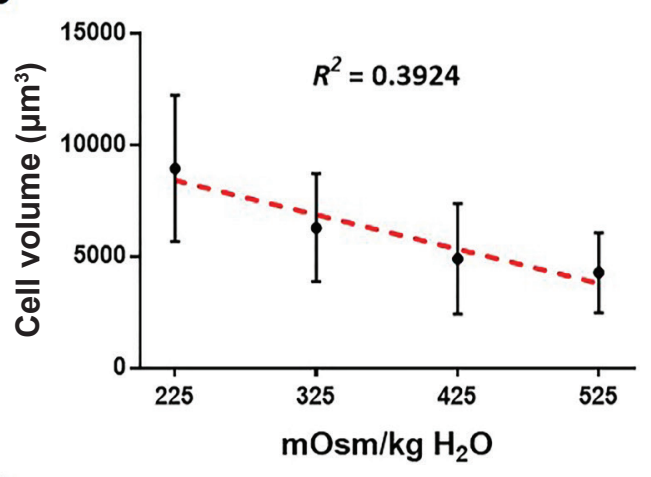

C

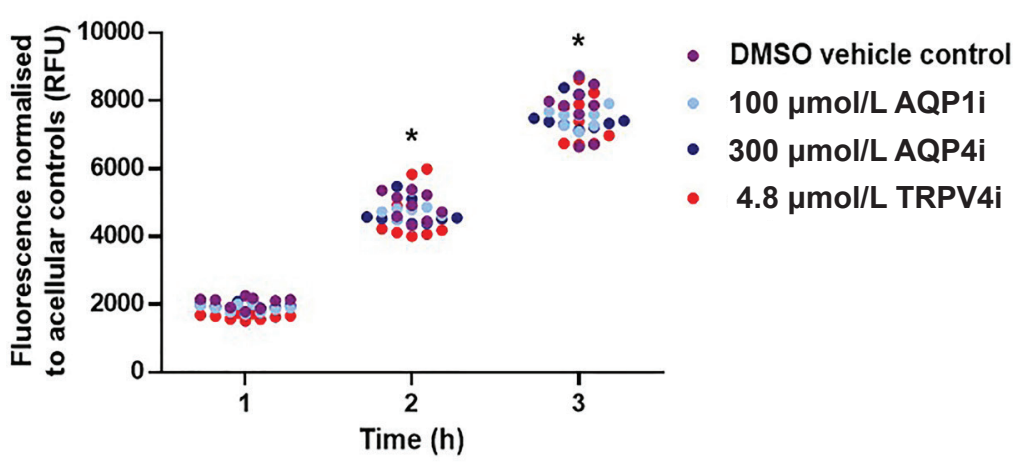

Fig. 4. Intracellular calcein fluorescence and cell volume correlation with extracellular osmolality and channel inhibitor viability in human NP cells. (a) Relative fluorescence $\left(\mathrm{F}_{1} / \mathrm{F}_{0}\right)$ of intracellular calcein depends linearly on extracellular osmolality. (b) NP-cell volume is not linearly correlated to extracellular osmolality. Average results for intracellular calcein $\mathrm{F}_{1} / \mathrm{F}_{0}$ and cell volume are plotted with standard deviation. Linear regression analysis is plotted as a dashed red line. (c) NP cell metabolic activity in response to DMSO vehicle control (purple), $100 \mu \mathrm{mol} / \mathrm{L}$ AQP1 inhibitor (AQP1i, light blue) (TC AQP1 1, Tocris Bioscience), $300 \mu \mathrm{mol} / \mathrm{L}$ AQP4 inhibitor (AQP4i, dark blue) (TGN 020, Tocris Bioscience) or $4.8 \mu \mathrm{mol} / \mathrm{L}$ TRPV4 inhibitor (TRPV4i, red) (HC-067047, Sigma-Aldrich) treatment for 1-3 h. Metabolic activity was measured using the resazurin reduction assay ( $n=3$ patients in triplicate). Significance determined by Kruskal-Wallis ${ }^{*} p \leq 0.05$. 

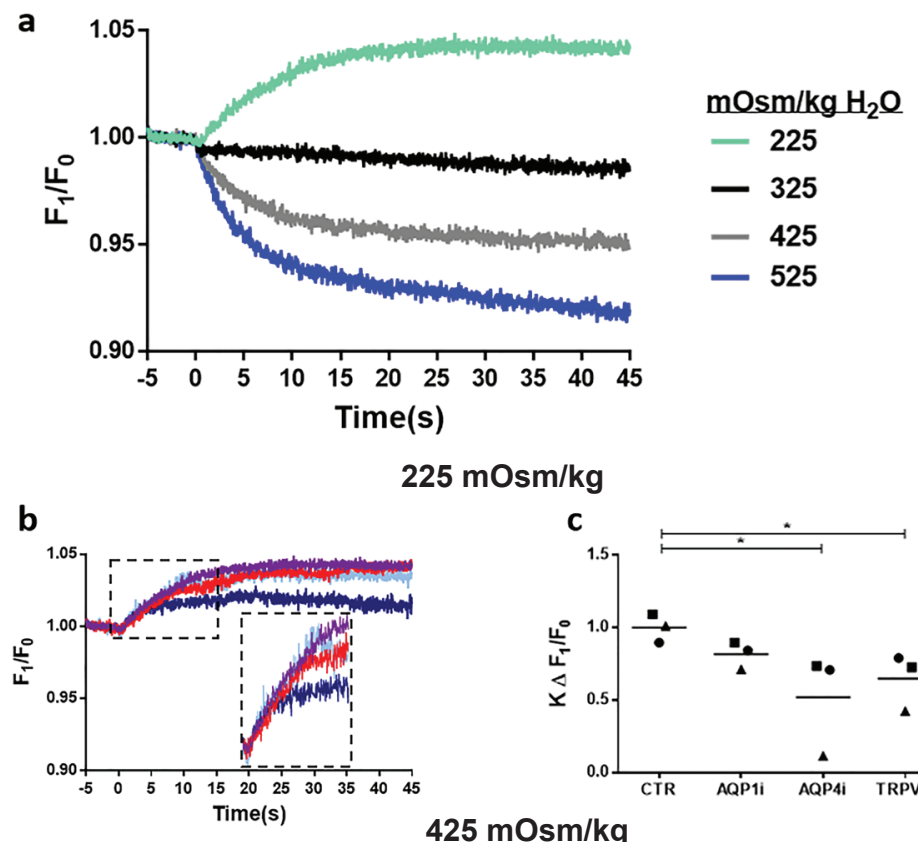

$225 \mathrm{mOsm} / \mathrm{kg}$

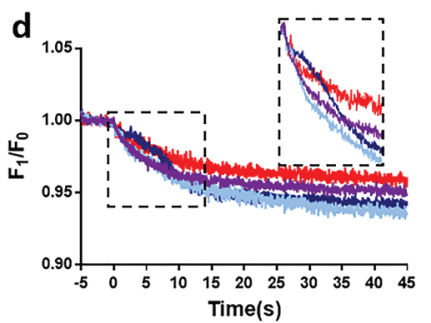

$425 \mathrm{mOsm} / \mathrm{kg}$
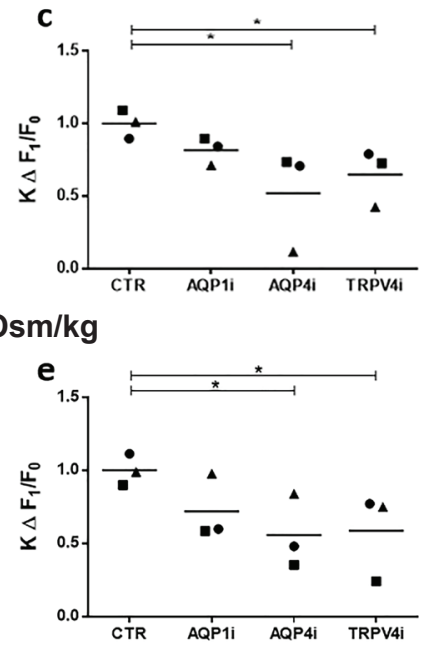

f

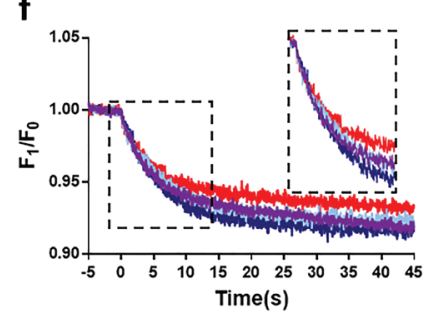

$525 \mathrm{mOsm} / \mathrm{kg}$

- Contro

- AQP1i

- AQP4i

- TRPV4i

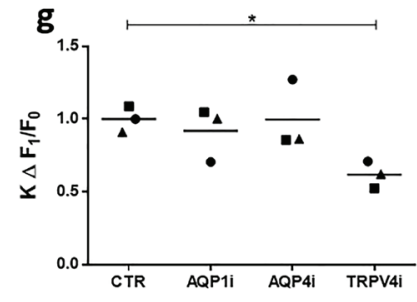

- Patient 1

- Patient 2

- Patient 3

Fig. 5. The rate of human NP cell swelling and shrinkage in response to extracellular osmolality changes. (a) The real-time rate of change in the relative fluorescence $\left(\mathrm{F}_{1} / \mathrm{F}_{0}\right)$ of intracellular calcein when NP cells are exposed to physiological alterations in extracellular osmolality $(225-525 \mathrm{mOsm} / \mathrm{kg})$. Baseline fluorescence of calcein-loaded NP cells was recorded for $5 \mathrm{~s}(-5-0 \mathrm{~s})$ before injection of altered osmolality media and change in calcein fluorescence recorded for a further $45 \mathrm{~s}(0-45 \mathrm{~s})$. The real-time change in intracellular calcein $\mathrm{F}_{1} / \mathrm{F}_{0}$ in NP cells when treated with (b) $225 \mathrm{mOsm} / \mathrm{kg}$, (d) $425 \mathrm{mOsm} / \mathrm{kg}$ and (f) $525 \mathrm{mOsm} / \mathrm{kg}$ media. The rate of change in intracellular calcein $\mathrm{F}_{1} / \mathrm{F}_{0}\left(\mathrm{~K} \Delta \mathrm{F}_{1} \mathrm{~F}_{0}\right)$ in NP cells when treated with (c) $225 \mathrm{mOsm} / \mathrm{kg}$, (e) $425 \mathrm{mOsm} /$ $\mathrm{kg}$ and $(\mathrm{g}) 525 \mathrm{mOsm} / \mathrm{kg}$ media. The real-time change in intracellular calcein $\mathrm{F}_{1} / \mathrm{F}_{0}$ in NP cells when treated with $225 \mathrm{mOsm} / \mathrm{kg}$ media. Change in $\mathrm{F}_{1} / \mathrm{F}_{0}$ was recorded in DMSO vehicle control (CTR, purple trace) cells and NP cells treated with $100 \mu \mathrm{mol} / \mathrm{L}$ AQP1 inhibitor (AQP1i, light blue trace), $300 \mu \mathrm{mol} / \mathrm{L}$ AQP4 inhibitor (AQP4i, dark blue trace) or $4.8 \mu \mathrm{mol} / \mathrm{L}$ TRPV4 inhibitor (TRPV4i, red trace) for $1 \mathrm{~h}$ prior to injection. The $\mathrm{K} \Delta \mathrm{F}_{1} \mathrm{~F}_{0}$ was determined from curves showing the real-time change in fluorescence of calcein, which is proportional to cell swelling and shrinkage in response to alterations in extracellular osmolality. Rate values were extrapolated by fitting plateau followed by one-phase association $(225 \mathrm{mOsm} / \mathrm{kg}) / \mathrm{decay}(425$, $525 \mathrm{mOsm} / \mathrm{kg}$ ) non-linear regression analysis to curves. $\mathrm{K} \Delta \mathrm{F}_{1} / \mathrm{F}_{0}$ was determined for 3 patient sample NP cells in triplicate, average values are plotted and normalised against no inhibition controls (CTR) for each treatment. Extracellular osmolality was altered for each treatment from a starting osmolality of $325 \mathrm{mOsm} /$ kg. Statistical significance determined between grouped data using Freidman test * $p \leq 0.05$. 


\section{Discussion}

The hyperosmotic environment of the IVD is constantly changing due to diurnal loading, where water is imbibed and then dissipated as the mechanical loading of the spine changes. In physiologically-matched osmolality, matrix expression is increased in NP cells (Neidlinger-Wilke et al., 2012; O'Connell et al., 2014; Wuertz et al., 2007), indicating NP cells have adapted their function to the hyper-osmotically fluctuating environment within the IVD. Therefore, mechanisms must be in place to protect NP cells, and enable their adaptation to hypo- and hyperosmotic shifts in extracellular osmolality. However, the mechanisms that control the initial response to altered extracellular osmolality, such as the rapid flux of water, ions, and changes in cell volume, are not completely understood in NP cells. Especially how hypo-osmotic conditions, observed during IVD degeneration, may impact on these fundamental cellular processes and the overall function of the IVD.

This study identified that NP cells rapidly modulate their cell volume and the rate at which volume is changed in response to extracellular osmolality. The magnitude of the rate of cell-volume change, actual cell-volume change and water permeability responses to extracellular osmolality alterations in NP cells was reliant upon the function of AQP4 and TRPV4, and less so AQP1. Under hypoosmotic treatment, AQP4i decreased NP-cell water permeability, maximum $\mathrm{Ca}^{2+}$ influx and time taken to reach maximum $\mathrm{Ca}^{2+}$ influx; this indicates that during degeneration, when osmolality and AQP4 expression is decreased (Snuggs et al., 2019), NP cells can no longer adapt to their environment. AQP1i showed similar trends in decreasing the water permeability of NP cells when exposed to hyper- and hypo-osmotic conditions. Yet, such trends were not significant compared to non-inhibition controls and were not of the same magnitude as AQP4i. This suggests AQP1 may still play an important role in RVD, but to a lesser extent than AQP4.

The expression of TRPV4 in human NP tissue was not sensitive to IVD degeneration and its function was required to maintain water permeability across all osmotic treatments, indicating TRPV4 enables fundamental cellular processes, such as volume regulation, regardless of IVD degeneration. Both TRPV4i and AQP4i decreased the water permeability

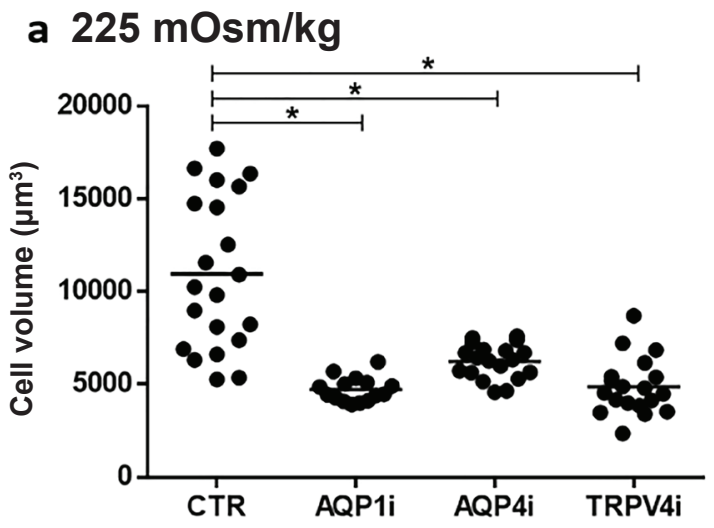

\section{b $325 \mathrm{mOsm} / \mathrm{kg}$}
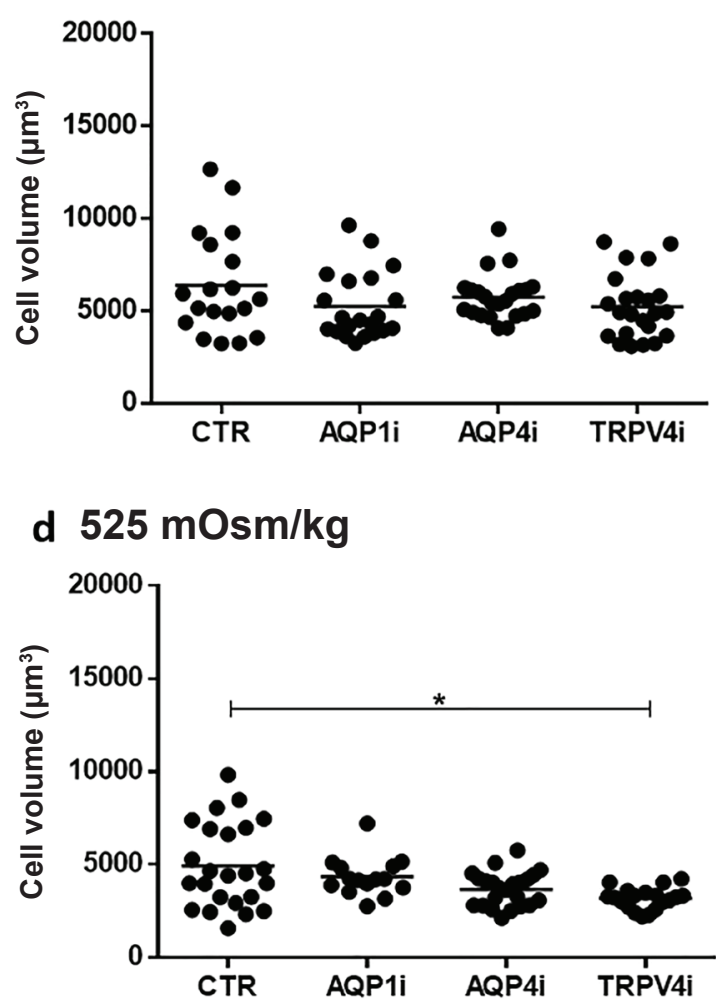

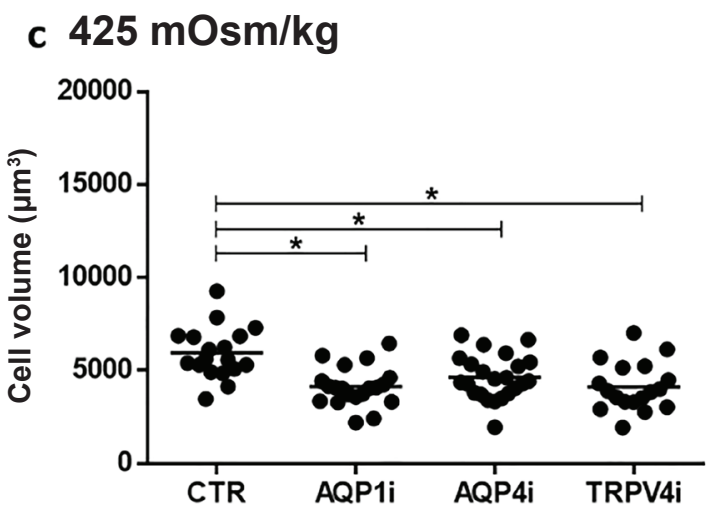

Fig. 6. NP cell volume changes in response to altered extracellular osmolality. Effect of AQP1 inhibition, AQP4 inhibition and TRPV4 inhibition on NP-cell volume, when compared to no inhibition DMSO vehicle controls (CTR), after standard culture medium (325 mOsm $/ \mathrm{kg}$ ) was altered to a final osmolality of (a) 225, (b) 325, (c) 425 and (d) $525 \mathrm{mOsm} / \mathrm{kg}$. NP cells were incubated with each inhibitor for $1 \mathrm{~h}$ prior to experiments. Cell volume was calculated from the area of 2D images of at least 200 CFSE-stained live NP cells in suspension from 3 patients in triplicate. Each point represents an individual image used for the analysis of cell volume. Statistical significance determined using Kruskal-Wallis test ${ }^{*} p \leq 0.05$. 


\section{a $225 \mathrm{mOsm} / \mathrm{kg}$}

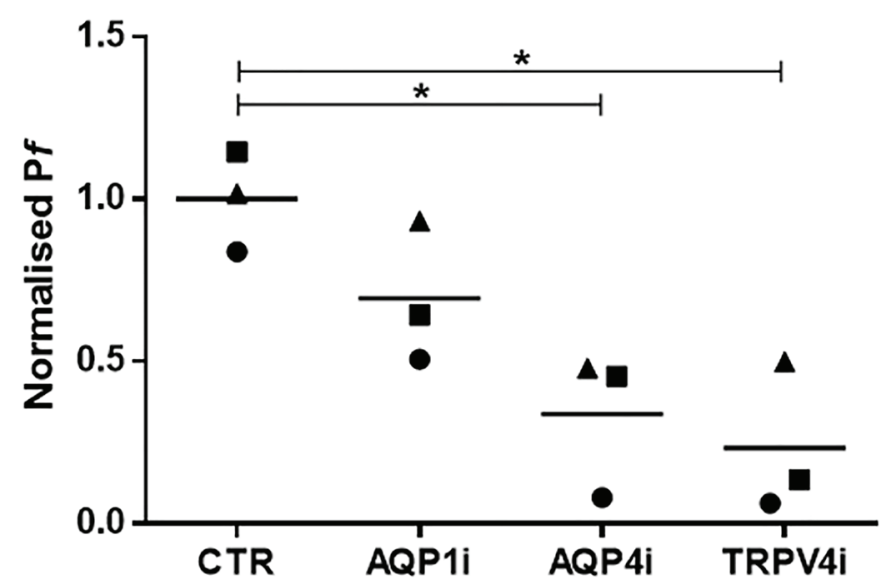

\section{b $425 \mathrm{mOsm} / \mathrm{kg}$}

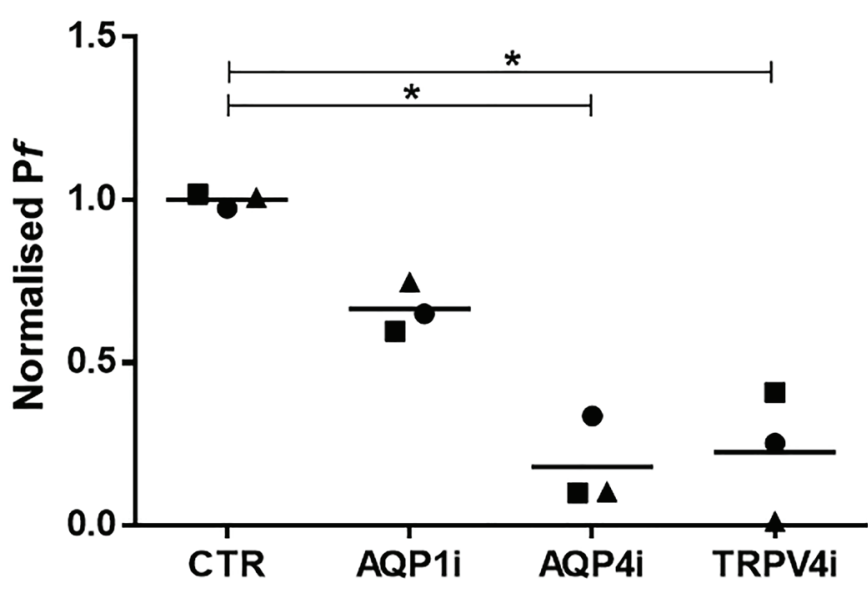

\section{c $525 \mathrm{mOsm} / \mathrm{kg}$}

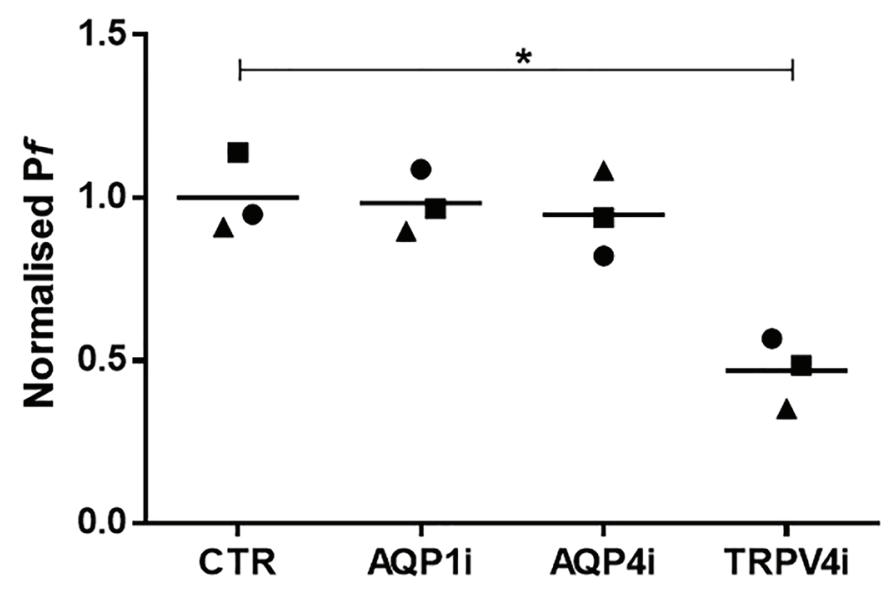

Fig. 7. Water permeability of human NP cells in response to extracellular osmolality alterations and the effect of AQP,1, 4 and TRPV4 inhibition. Water permeability (Pf) is calculated using the rate of change in calcein fluorescence (K $\Delta \mathrm{F} 1 / \mathrm{F} 0)$, the actual change in cell volume and cell surface area, after alterations to extracellular osmolality, and applied to the equation developed by Fenton et al. (2010). All Pf values were normalised to the average of no inhibition DMSO vehicle controls (CTR) and averaged per patient. The normalised Pf of AQP1 inhibition, AQP4 inhibition and TRPV4 inhibition was compared to CTR at (a) 225, (b) 425 and (c) $525 \mathrm{mOsm} / \mathrm{kg}$ treatments. Prior to treatment, medium osmolality was $325 \mathrm{mOsm} / \mathrm{kg}$. Statistical significance determined between grouped data using Friedman test $p \leq 0.05$. 


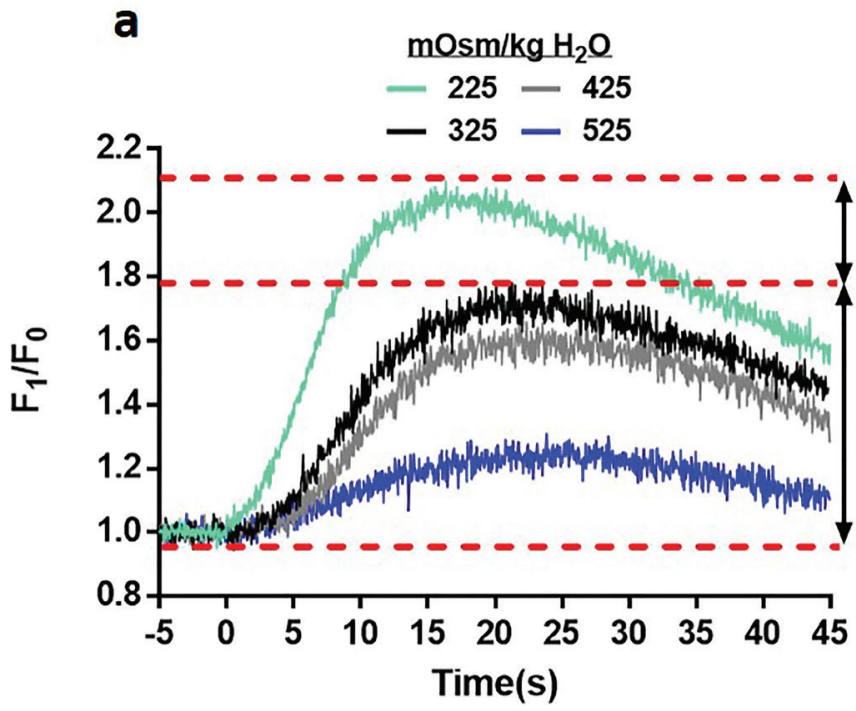

d

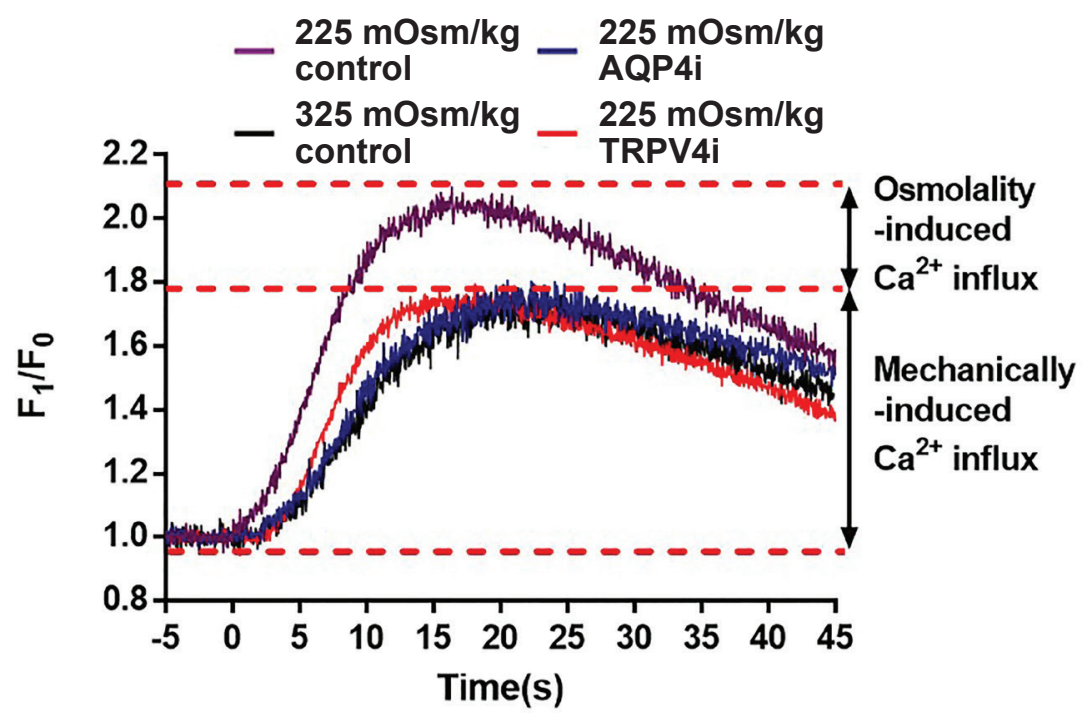

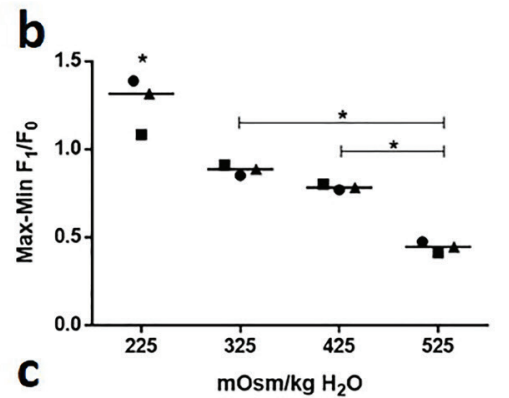

Mechanically

-induced

$\mathrm{Ca}^{2+}$ influx

- Patient 1

- Patient 2

\ Patient 3
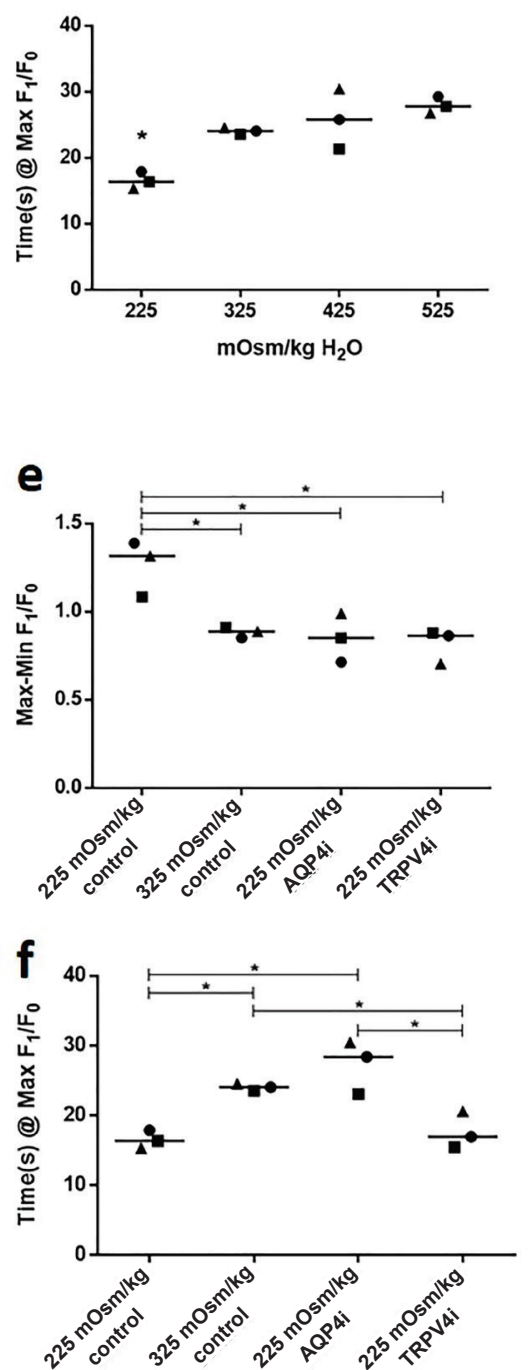

Fig. 8. $\mathrm{Ca}^{2+}$ influx in human NP cells when exposed to altered extracellular osmolality. (a) Fluo-4 direct assay (Invitrogen) was used to measure the rate of $\mathrm{Ca}^{2+}$ influx into human NP cells. Baseline fluorescence of calcein-loaded NP cells was recorded for $5 \mathrm{~s}(-5-0 \mathrm{~s})$, before injection of altered osmolality media and change in relative Fluo-4 fluorescence $\left(\mathrm{F}_{1} / \mathrm{F}_{0}\right)$, dependent on the intracellular $\mathrm{Ca}^{2+}$ concentration, was recorded for a further $45 \mathrm{~s}(0-45 \mathrm{~s})$. (b) Max-min $\mathrm{F}_{1} / \mathrm{F}_{0}$ values for $\mathrm{Ca}^{2+}$ influx at each treatment osmolality, indicating total $\mathrm{Ca}^{2+}$ influx over time. (c) Time (s) taken for max $\mathrm{F}_{1} / \mathrm{F}_{0}\left(\mathrm{Ca}^{2+}\right.$ influx) to be reached in human NP cells at each treatment osmolality. (d) The rate of $\mathrm{Ca}^{2+}$ influx into human NP cells when treated with $225 \mathrm{mOsm} / \mathrm{kg}$ control (purple trace), $325 \mathrm{mOsm} / \mathrm{kg}$ control (black trace), $225 \mathrm{mOsm} / \mathrm{kg}$ AQP4 inhibitor (dark blue trace) and TRPV4 inhibitor (red trace). (e) Max-min $\mathrm{F}_{1} / \mathrm{F}_{0}$ values for $\mathrm{Ca}^{2+}$ influx in NP cells when treated with channel inhibitors compared to osmotic DMSO vehicle controls. (f) Time (s) taken for max $\mathrm{F}_{1} / \mathrm{F}_{0}\left(\mathrm{Ca}^{2+}\right.$ influx) to be reached in human NP cells when treated with channel inhibitors compared to osmotic controls. Averaged triplicate values from 3 patients were plotted. Statistical significance determined between grouped data using Kruskal-Wallis test $* \leq 0.05$. 
and hypo-osmotic $\mathrm{Ca}^{2+}$ influx in NP cells. Both channels also co-localised with each other and potentially with primary cilia. This suggests that the function of both channels is linked and may play joint roles during NP-cell adaptation to its osmotic microenvironment, in which the primary cilia may also perform an important role (Choi et al., 2019; Corrigan et al., 2018; Li et al., 2020).

\section{NP cell volume change in response to extracellular osmolality and the role of AQP1, 4 and TRPV4}

Human NP cells increased cell volume under hypo-osmotic and decreased under hyperosmotic conditions, similar to that seen in other cells (Corasanti et al., 1990; Lang et al., 1998). Bovine NP cells show a similar trend when exposed to low osmolality (Maidhof et al., 2014) and rabbit NP cell size was also increased after an annulus fibrosus puncture model of degeneration (He et al., 2013). This indicates that during IVD degeneration, when osmolality is decreased, cell size may increase and NP cell size could be used to indicate the degenerative state of the IVD.

When exposed to decreased extracellular osmolality (225 mOsm/kg), NP cell volume was increased compared to osmotic controls (325 mOsm/ $\mathrm{kg}$ ). In the presence of either AQP1i, AQP4i or TRPV4i, the hypo-osmotic increase in NP-cell size was not observed. Highlighting the inhibition of these channels prevents the size of NP cells increasing when exposed to a hypo-osmotic stimulus. These results indicate that the function of both AQP1, 4 and TRPV4 is required for NP cells to respond in the correct manner to decreased osmolality, by increasing volume. This potentially indicates that these channels work synergistically, enabling NP cells to correctly regulate their volume and trigger downstream mechanisms (such as RVD), in order to adapt to their environment. Such synergistic functions of AQP1, 4 and TRPV4 has been observed in astrocytes and the regulation of the blood-brain-barrier previously (Jo et al., 2015; Kitchen et al., 2015; Mola et al., 2016; Solenov et al., 2004). Furthermore, channel inhibition of AQP1, 4 and TRPV4 significantly reduced the volume of NP cells exposed to $425 \mathrm{mOsm} / \mathrm{kg}$ media when compared to no-inhibition controls, indicating that the function of all 3 channels is also required for NP cells to alter their volume correctly to a hyperosmotic environment (mimicking the healthy IVD). At $525 \mathrm{mOsm} / \mathrm{kg}$ (also mimicking the healthy IVD) only TRPV4i significantly altered NP-cell volume compared to no-inhibition controls. Along with the native expression of TRPV4 being insensitive to IVD degeneration, this indicates that TRPV4 function may be important for fundamental volume regulation processes, regardless of IVD health. Whereas the function of both AQP1 and 4 appears to be significant within a smaller osmotic range; possibly due to changes in membrane tension (caused by altered osmolality) modulating water flow (Ozu et al., 2018).

\section{The rate of NP cell volume change in response to altered osmolality and the role of AQP1, 4 and TRPV4}

This is the first time the rate of NP-cell volume change in response to altered osmolality, and the effects of AQP1, 4 and TRPV4 inhibition, has been investigated. The rate of NP-cell swelling and shrinkage was determined using calcein-AM loaded cells. Calcein-AM has been used in experimental systems to determine rapid changes in volume and AQP function (Chen and Knutson, 1988; Hamann et al., 2002; Solenov et al., 2004; Zeidel et al., 1992). These measurements are achieved by the self-quenching properties of calcein at higher concentrations (Chen and Knutson, 1988) and insensitivity to $\mathrm{pH}, \mathrm{Ca}^{2+}$ or $\mathrm{NaCl}$ concentration (Solenov et al., 2004; Wehner et al., 1995). Calcein fluorescence depends linearly on extracellular osmolality in MDKC cells (Fenton et al., 2010), which has also been shown for human NP cells in this study. Thus, demonstrating these methods can be used to accurately investigate the fundamental functions of NP cells, regarding how they respond to their osmotically fluxing environment, and what molecules/proteins/pathways contribute to their adaptation. One caveat to this technique is that it is performed on 2D-cultured cells, therefore cell volume and the rate at which it changes may not represent how NP cells respond in their in vivo environment.

AQP4 function was required for NP cells to swell at the normal rate under $225 \mathrm{mOsm} / \mathrm{kg}$ treatments and shrink at the normal rate under $425 \mathrm{mOsm} /$ $\mathrm{kg}$ treatment. TRPV4 function was required for NP cells to alter their volume at the correct rate across all osmotic treatments $(225,425$ and $525 \mathrm{mOsm} / \mathrm{kg})$. This highlighted that AQP4 and TRPV4 not only contribute to overall NP-cell volume, but also dictate the rate at which the desired volume is reached, further implicating both channels in the control of NP-cell responses to the osmotic environment. The function of AQP1 is yet to be fully elucidated as inhibition did not significantly change the rate of NP-cell volume change.

\section{Control of NP-cell water permeability}

The water permeability of NP cells was determined by combining actual cell volume changes and the rates of change in volume, as cell volume cannot be directly determined from calcein fluorescence in MDCK cells (Fenton et al., 2010) or in NP cells, as shown in this study. AQP4i decreased the water permeability of NP cells when exposed to healthy (425 mOsm/ $/ \mathrm{kg})$ and degenerate $(225 \mathrm{mOsm} / \mathrm{kg}$ ) osmolalities, but not when NP cells were exposed to higher osmolality (525 mOsm $/ \mathrm{kg}$ ). AQP1i treatment followed a similar trend to AQP4i but was not significant. This may indicate that AQP4 (and potentially AQP1 to a lesser extent) only controls NP-cell responses under specific conditions within the microenvironment of the IVD. AQP4 has a higher water permeability than AQP1 (Kitchen et al., 2015; Yang and Verkman, 1997), so therefore may have a larger contribution 
towards NP cell control when compared to AQP1. It has previously been shown that AQP4 driven water permeability may depend on cell membrane compression and tension (Ozu et al., 2018; Tong et al., 2012), which changes as cells respond to altered osmolality. Thus, AQP4 may exert a greater effect on NP cells within a certain osmotic range, and multiple other AQPs expressed by NP cells may contribute outside this range (Snuggs et al., 2019).

TRPV4 function on the other hand, significantly impacted on the water permeability of NP cells across all osmolalities and was expressed by the vast majority of NP cells regardless of degenerative state. This indicates a potential overarching role during NPcell physiology and adaptation to the hyperosmotic environment of the IVD. TRPV4 is known to enable chondrocyte mechanotransduction and matrix synthesis (O'Conor et al., 2014) and lack of TRPV4 expression can induce osteoarthritis in animal models (Clark et al., 2010; Lamandé et al., 2011), and therefore may contribute to similar functions in the IVD. TRPV4 contributes to NP cell water permeability, yet it is not a water channel itself. Therefore, TRPV4 function must somehow be linked to the function of AQPs and cell-volume regulation. TRPV4 has been shown to have physical and functional links with AQPs to enable cells to sense extracellular osmolality changes and initiate cell-volume responses (Benfenati et al., 2011; Galizia et al., 2012; Jo et al., 2015; Liu et al., 2006; Mola et al., 2016). TRPV4 was also found to co-localise with AQP4 in human NP cells suggesting related functions and interaction between both channels. The localisation of both AQP4 and TPRV4 within NP cells also appeared to match the morphological appearance of primary cilia, indicating for the first time that AQP4 co-localises with primary cilia in NP cells. This suggests the osmo- and mechano-sensing roles of primary cilia may be modulated by the function of AQP4 in NP cells.

Increased osmolality treatments (425 and $525 \mathrm{mOsm} / \mathrm{kg}$ ) used in these experiments were produced using sucrose as the key osmolyte. This ensured that the actual water permeability of NP cells could be determined. NP cells contain transmembrane channel proteins that readily transport osmolytes such as $\mathrm{Na}^{+}$and $\mathrm{Cl}$, urea and mannitol. Therefore, if any of these were used to alter osmotic treatments, cell volume may have reached equilibrium at a different rate, as NP cells could utilise the movement of osmolytes used to regulate volume changes, rather than employing the actual mechanisms used to regulate cell volume. However, as the IVD matrix is negatively charged, one of the main ions imbibed into the tissue is $\mathrm{Na}^{+}$(Urban, 2002). So repeating experiments using $\mathrm{NaCl}$ will enable the comparison between methods of changing medium osmolality (determining if results are an osmotic or substrate effect) and may be more physiological to the in vivo environment of the IVD.

\section{$\mathrm{Ca}^{2+}$ influx in response to extracellular osmotic shifts}

An important cellular response to osmotic shifts in their extracellular environment is to modulate calcium flux to trigger downstream pathways to enable adaptation to altering the environment in which TRPV4 has an established role (Arniges et al., 2004; Caterina et al., 1997; Everaerts et al., 2010; Liedtke and Friedman, 2003; Toft-Bertelsen et al., 2018). NP cells showed they also increase $\mathrm{Ca}^{2+}$ influx under hypo-osmotic conditions, compared to hyper-osmotic conditions, suggesting they may employ similar pathways to adapt to their diurnal environment. Previous research has also shown that NP cells do not increase calcium influx under similar hyperosmotic conditions (Pritchard et al., 2002). Pritchard et al. (2002) also identified that $\mathrm{Ca}^{2+}$ influx and cell volume may be controlled by an actin cytoskeletal-dependent mechanism. Which, in turn, could potentially be regulated by AQP4. In astrocytes, AQP4 knockdown leads to actin cytoskeleton rearrangement and reduced water permeability (Nicchia et al., 2005). Cytoskeletal rearrangement under alterations in osmolality have also been observed in bovine NP cells (Maidhof et al., 2014). However, when NP cells were injected with control media (325 mOsm $/ \mathrm{kg}$, same as pre-injection media) a $\mathrm{Ca}^{2+}$ influx response was still observed. This highlights that $\mathrm{Ca}^{2+}$ influx may also be due to mechanical pressure applied onto NP cells from the injection system of the plate reader, as TRPV4 and other $\mathrm{Ca}^{2+}$ channels are also known to be mechanotransducive (Samanta et al., 2018). This may indicate that the $\mathrm{Ca}^{2+}$ influx observed was not solely attributable to the extracellular osmolality; however, hypo-osmotic increased $\mathrm{Ca}^{2+}$ influx to a greater extent than the $325 \mathrm{mOsm} / \mathrm{kg}$ control injection.

TRPV4i significantly reduced hypo-osmotic $\mathrm{Ca}^{2+}$ influx, suggesting important NP-cell responses to hypo-osmotic stimuli and the potential activation of RVD. However, $\mathrm{Ca}^{2+}$ influx was not totally nullified; therefore, other channels may also be involved in these processes. Also, TRPV4-induced $\mathrm{Ca}^{2+}$ influx is only the start of RVD mechanisms. This is followed by activation of $\mathrm{Ca}^{2+}$-dependent $\mathrm{K}^{+}$channels (Arniges et al., 2004) to restore intra- and extracellular osmotic pressure. Yet, at present, it is unknown what $\mathrm{K}^{+}$ channels contribute or how this is achieved in IVD cells.

AQP4i significantly reduced the time taken for maximum $\mathrm{Ca}^{2+}$ influx and the maximum $\mathrm{Ca}^{2+}$ influx, despite its sole function as a water channel. AQP4 and TRPV4 function is linked to osmosensing of astrocytes (Benfenati et al., 2011; Chmelova et al., 2019; Jo et al., 2015; Mola et al., 2016), and results described here indicate that there may be similar mechanisms employed by NP cells. Such mechanisms may be coordinated by primary-cilia signalling and facilitated by AQP4 co-localisation. Primary cilia are known to contribute towards osmo- and mechano- 
sensing pathways (McGlashan et al., 2010; Narita et al., 2010; Siroky et al., 2017), yet their roles regarding cell function within the IVD have only recently emerged (Choi et al., 2019; Li et al., 2020) and remain to be fully elucidated.

\section{Conclusion}

AQP1, 4 and TRPV4 function may be linked to the ability of NP cells to control the rate of cell volume regulation, water permeability and $\mathrm{Ca}^{2+}$ influx, triggering downstream mechanisms enabling the adaptation of NP cells to their osmotically challenging environment. During IVD degeneration AQP1 and AQP4 expression are decreased (Johnson et al., 2015; Snuggs et al., 2019); as a result, NP cells will not be able to respond to the hypo-osmotic environment due to impaired cell volume regulation, water permeability and $\mathrm{Ca}^{2+}$ influx. Due to the lack of an osmotic response, downstream mechanisms may not be employed by NP cells to ensure their survival and function in the increasingly degenerate environment. Further study is warranted to determine what impact AQP1, 4 and TRPV4 expression and function have on potential downstream mechanisms such as RVD, cell survival and matrix synthesis in NP cells, and how these mechanisms contribute to IVD health and degeneration.

\section{Acknowledgements}

The Authors would like to thank the surgeons: $\mathrm{Mr}$ Ashley Cole, Mr Neil Chiverton, Mr Antony Michael, Mr Lee Breakwell, Mr Michael Athanassacopoulos, Mr Marcel Ivanov and Mr James Tomlinson from Northern General Hospital, Sheffield Teaching Hospitals NHS Trust for the supply of human disc samples. The authors would like to thank Sheffield Hallam University Vice Chancellors Scholarship for funding this research.

\section{References}

Agre P, King LS, Yasui M, Guggino WB, Ottersen OP, Fujiyoshi Y, Engel A, Nielsen S (2002) Aquaporin water channels - from atomic structure to clinical medicine. J Physiol 542: 3-16.

Arniges M, Vázquez E, Fernández-Fernández JM, Valverde MA (2004) Swelling-activated $\mathrm{Ca}^{2+}$ entry via TRPV4 channel is defective in cystic fibrosis airway epithelia. J Biol Chem 279: 54062-54068.

Benfenati V, Caprini M, Dovizio M, Mylonakou MN, Ferroni S, Ottersen OP, Amiry-Moghaddam M (2011) An aquaporin-4/transient receptor potential vanilloid 4 (AQP4/TRPV4) complex is essential for cell-volume control in astrocytes. Proc Natl Acad Sci U S A 108: 2563-2568.
Binch A, Snuggs J, Le Maitre CL (2020) Immunohistochemical analysis of protein expression in formalin fixed paraffin embedded human intervertebral disc tissues. JOR Spine 3: e1098. DOI: 10.1002/jsp2.1098.

Caterina MJ, Schumacher MA, Tominaga M, Rosen TA, Levine JD, Julius D (1997) The capsaicin receptor: a heat-activated ion channel in the pain pathway. Nature 389: 816-824.

Chen RF, Knutson JR (1988) Mechanism of fluorescence concentration quenching of carboxyfluorescein in liposomes: energy transfer to nonfluorescent dimers. Anal Biochem 172: 61-77.

Chmelova M, Sucha P, Bochin M, Vorisek I, Pivonkova H, Hermanova Z, Anderova M, Vargova L (2019) The role of aquaporin-4 and transient receptor potential vaniloid isoform 4 channels in the development of cytotoxic edema and associated extracellular diffusion parameter changes. Eur J Neurosci 50: 1685-1699.

Choi H, Madhu V, Shapiro IM, Risbud MV (2019) Nucleus pulposus primary cilia alter their length in response to changes in extracellular osmolarity but do not control TonEBP-mediated osmoregulation. Sci Rep 9: 15469. DOI: 10.1038/s41598-019-51939-7.

Clark AL, Votta BJ, Kumar S, Liedtke W, Guilak F (2010) Chondroprotective role of the osmotically sensitive ion channel transient receptor potential vanilloid 4: age- and sex-dependent progression of osteoarthritis in Trpv4-deficient mice. Arthritis Rheum 62: 2973-2983.

Corasanti JG, Gleeson D, Boyer JL (1990) Effects of osmotic stresses on isolated rat hepatocytes. I. Ionic mechanisms of cell volume regulation. Am J Physiol 258: G290-G298.

Corrigan MA, Johnson GP, Stavenschi E, Riffault M, Labour MN, Hoey DA (2018) TRPV4-mediates oscillatory fluid shear mechanotransduction in mesenchymal stem cells in part via the primary cilium. Sci Rep 8: 3824. DOI: 10.1038/s41598-01822174-3.

Day RE, Kitchen P, Owen DS, Bland C, Marshall L, Conner AC, Bill RM, Conner MT (2014) Human aquaporins: regulators of transcellular water flow. Biochim Biophys Acta 1840: 1492-1506.

Delling M, Decaen PG, Doerner JF, Febvay S, Clapham DE (2013) Primary cilia are specialized calcium signalling organelles. Nature 504: 311-314.

Donnelly E, Williams R, Farnum C (2008) The primary cilium of connective tissue cells: Imaging by multiphoton microscopy. Anat Rec (Hoboken) 291: 1062-1073.

Everaerts W, Nilius B, Owsianik G (2010) The vanilloid transient receptor potential channel TRPV4: from structure to disease. Prog Biophys Mol Biol 103: 2-17.

Fenton RA, Moeller HB, Nielsen S, de Groot BL, Rützler M (2010) A plate reader-based method for cell water permeability measurement. Am J Physiol Renal Physiol 298: F224-F230. 
Gajghate S, Hiyama A, Shah M, Sakai D, Anderson DG, Shapiro IM, Risbud M V (2009) Osmolarity and intracellular calcium regulate aquaporin2 expression through TonEBP in nucleus pulposus cells of the intervertebral disc. J Bone Miner Res 24: 992-1001.

Galán-Cobo A, Ramírez-Lorca R, Echevarría M (2016) Role of aquaporins in cell proliferation: What else beyond water permeability? Channels (Austin) 10: 185-201.

Galizia L, Pizzoni A, Fernandez J, Rivarola V, Capurro C, Ford P (2012) Functional interaction between AQP2 and TRPV4 in renal cells. J Cell Biochem 113: 580-589.

Gan Y, Tu B, Li P, Ye J, Zhao C, Luo L, Zhang C, Zhang Z, Zhu L, Zhou Q (2018) Low magnitude of compression enhances biosynthesis of mesenchymal stem cells towards nucleus pulposus cells via the TRPV4-dependent pathway. Stem Cells Int 2018: 1-12. DOI: 10.1155/2018/7061898.

Gilbert HTJ, Hoyland JA, Freemont AJ, MillwardSadler SJ (2011) The involvement of interleukin-1 and interleukin- 4 in the response of human annulus fibrosus cells to cyclic tensile strain: an altered mechanotransduction pathway with degeneration. Arthritis Res. Ther 13: R8. DOI: 10.1186/ar3229.

Gilbert HTJ, Hoyland JA, Millward-Sadler SJ (2010) The response of human anulus fibrosus cells to cyclic tensile strain is frequency-dependent and altered with disc degeneration. Arthritis Rheum 62: 3385-3394.

Hamann S, Kiilgaard JF, Litman T, AlvarezLeefmans FJ, Winther BR, Zeuthen T (2002) Measurement of cell volume changes by fluorescence self-quenching. J Fluoresc 12: 139-145.

He B, Wang Y, Yang J, Peng F, Li F (2013) Normal and degenerated rabbit nucleus pulposus cells in in vitro cultures: a biological comparison. J Huazhong Univ Sci Technolog Med Sci 33: 228-233.

Ishihara H, Warensjo K, Roberts S, Urban JP (1997) Proteoglycan synthesis in the intervertebral disk nucleus: the role of extracellular osmolality. Am J Physiol Physiol 272: C1499-C1506.

Jo AO, Ryskamp DA, Phuong TTT, Verkman AS, Yarishkin XO, Macaulay N, Križaj D (2015) Cellular/ molecular TRPV4 and AQP4 channels synergistically regulate cell volume and calcium homeostasis in retinal Müller glia. J Neurosci 35: 13525-13537.

Johnson ZI, Gogate SS, Day R, Binch A, Markova DZ, Chiverton N, Cole A, Conner M, Shapiro IM, Le Maitre CL, Risbud M V (2015) Aquaporin 1 and 5 expression decreases during human intervertebral disc degeneration: novel HIF-1-mediated regulation of aquaporins in NP cells. Oncotarget 6: 11945-11958.

Kitchen P, Day RE, Salman MM, Conner MT, Bill RM, Conner AC (2015) Beyond water homeostasis: diverse functional roles of mammalian aquaporins. Biochim Biophys Acta 1850: 2410-2421.

Kitchen P, Conner AC (2015) Control of the aquaporin- 4 channel water permeability by structural dynamics of aromatic/arginine selectivity filter residues. Biochemistry 54: 6753-6755.
Kleene SJ, Siroky BJ, Landero-Figueroa JA, Dixon BP, Pachciarz NW, Lu L, Kleene NK (2019) The TRPP2-dependent channel of renal primary cilia also requires TRPM3. PLoS One 14: e0214053. DOI: 10.1371/journal.pone.0214053.

Köhler R, Heyken W-T, Heinau P, Schubert R, Si H, Kacik M, Busch C, Grgic I, Maier T, Hoyer J (2006) Evidence for a functional role of endothelial transient receptor potential V4 in shear stress-induced vasodilatation. Arterioscler. Thromb. Vasc. Biol. 26: 1495-1502.

Krane CM, Melvin JE, Nguyen HV, Richardson L, Towne JE, Doetschman T, Menon AG (2001) Salivary acinar cells from aquaporin 5-deficient mice have decreased membrane water permeability and altered cell volume regulation. J Biol Chem 276: 23413-23420.

Lamandé SR, Yuan Y, Gresshoff IL, Rowley L, Belluoccio D, Kaluarachchi K, Little CB, Botzenhart E, Zerres K, Amor DJ, Cole WG, Savarirayan R, McIntyre P, Bateman JF (2011) Mutations in TRPV4 cause an inherited arthropathy of hands and feet. Nat Genet 43: 1142-1146.

Lang F, Busch GL, Ritter M, Völkl H, Waldegger S, Gulbins E, Häussinger D (1998) Functional significance of cell volume regulatory mechanisms. Physiol Rev 78: 247-306.

Lewis R, Feetham CH, Barrett-Jolley R (2011) Cell volume regulation in chondrocytes. Cell Physiol Biochem 28: 1111-1122.

Li X, Yang S, Han L, Mao K, Yang S (2020) Ciliary IFT80 is essential for intervertebral disc development and maintenance. FASEB J 34: 6741-6756.

Liedtke W, Choe Y, Martí-Renom MA, Bell AM, Denis CS, Sali A, Hudspeth AJ, Friedman JM, Heller S (2000) Vanilloid receptor-related osmotically activated channel (VR-OAC), a candidate vertebrate osmoreceptor. Cell 103: 525-535.

Liedtke W, Friedman JM (2003) Abnormal osmotic regulation in trpv4-/- mice. Proc Natl Acad Sci U S A 100: 13698-13703.

Liu X, Bandyopadhyay BC, Bandyopadhyay B, Nakamoto T, Singh B, Liedtke W, Melvin JE, Ambudkar I (2006) A role for AQP5 in activation of TRPV4 by hypotonicity: concerted involvement of AQP5 and TRPV4 in regulation of cell volume recovery. J Biol Chem 281: 15485-15495.

Livak KJ, Schmittgen TD (2001) Analysis of relative gene expression data using real-time quantitative PCR and the 2(-Delta Delta C(T)) method. Methods 25: 402-408.

Maidhof R, Jacobsen T, Papatheodorou A, Chahine NO (2014) Inflammation induces irreversible biophysical changes in isolated nucleus pulposus cells. PLoS One 9: e99621. DOI: 10.1371/journal. pone.0099621.

Le Maitre CL, Frain J, Millward-Sadler J, Fotheringham AP, Freemont AJ, Hoyland JA (2009) Altered integrin mechanotransduction in human nucleus pulposus cells derived from degenerated discs. Arthritis Rheum 60: 460-469. 
Le Maitre CL, Freemont AJ, Hoyland JA (2007) Accelerated cellular senescence in degenerate intervertebral discs: a possible role in the pathogenesis of intervertebral disc degeneration. Arthritis Res Ther 9: R45. DOI: 10.1186/ar2198.

McGlashan SR, Knight MM, Chowdhury TT, Joshi P, Jensen CG, Kennedy S, Poole CA (2010) Mechanical loading modulates chondrocyte primary cilia incidence and length. Cell Biol Int 34: 441-446.

McMillan DW, Garbutt G, Adams MA (1996) Effect of sustained loading on the water content of intervertebral discs: implications for disc metabolism. Ann Rheum Dis 55: 880-887.

Mola MG, Sparaneo A, Gargano CD, Spray DC, Svelto M, Frigeri A, Scemes E, Nicchia GP (2016) The speed of swelling kinetics modulates cell volume regulation and calcium signaling in astrocytes: a different point of view on the role of aquaporins. Glia 64: 139-154.

Narita K, Kawate T, Kakinuma N, Takeda S (2010) Multiple primary cilia modulate the fluid transcytosis in choroid plexus epithelium. Traffic 11: 287-301.

Nauli SM, Pala R, Kleene SJ (2016) Calcium channels in primary cilia. Curr Opin Nephrol Hypertens 25: 452-458.

Neidlinger-Wilke C, Mietsch A, Rinkler C, Wilke H-J, Ignatius A, Urban J (2012) Interactions of environmental conditions and mechanical loads have influence on matrix turnover by nucleus pulposus cells. J Orthop Res 30: 112-121.

Nicchia GP, Srinivas M, Li W, Brosnan CF, Frigeri A, Spray DC (2005) New possible roles for aquaporin-4 in astrocytes: cell cytoskeleton and functional relationship with connexin43. FASEB J 19: 1674-1676.

Nilius B, Prenen J, Wissenbach U, Bödding M, Droogmans G (2001) Differential activation of the volume-sensitive cation channel TRP12 (OTRPC4) and volume-regulated anion currents in HEK-293 cells. Pflugers Arch 443: 227-233.

O'Connell GD, Newman IB, Carapezza MA (2014) Effect of long-term osmotic loading culture on matrix synthesis from intervertebral disc cells. Biores Open Access 3: 242-249.

O'Conor CJ, Leddy HA, Benefield HC, Liedtke WB, Guilak F (2014) TRPV4-mediated mechanotransduction regulates the metabolic response of chondrocytes to dynamic loading. Proc Natl Acad Sci U S A 111: 1316-1321.

Ozu M, Galizia L, Acuña C, Amodeo G (2018) Aquaporins: more than functional monomers in a tetrameric arrangement. Cells 7: 209. DOI: 10.3390/ cells7110209.

Pablo JL, DeCaen PG, Clapham DE (2017) Progress in ciliary ion channel physiology. J Gen Physiol 149: 37-47.

Pritchard S, Erickson GR, Guilak F (2002) Hyperosmotically induced volume change and calcium signaling in intervertebral disk cells: the role of the actin cytoskeleton. Biophys J 83: 2502-2510.
Richardson SM, Knowles R, Marples D, Hoyland JA, Mobasheri A (2008) Aquaporin expression in the human intervertebral disc. J Mol Histol 39: 303-309.

Sadowska A, Kameda T, Krupkova O, WuertzKozak (2018) Osmosensing, osmosignalling and inflammation: how intervertebral disc cells respond to altered osmolarity. Eur Cell Mater 36: 231-250.

Samanta A, Hughes TET, Moiseenkova-Bell VY (2018) Transient receptor potential (TRP) channels. Subcell Biochem 87: 141-165.

Schneider CA, Rasband WS, Eliceiri KW (2012) NIH Image to ImageJ: 25 years of image analysis. Nat Methods 9: 671-675.

Siroky BJ, Kleene NK, Kleene SJ, Varnell CD, Comer RG, Liu J, Lu L, Pachciarz NW, Bissler JJ, Dixon BP (2017) Primary cilia regulate the osmotic stress response of renal epithelial cells through TRPM3. Am J Physiol Renal Physiol 312: F791-F805.

Snuggs JW, Day RE, Bach FC, Conner MT, Bunning RAD, Tryfonidou MA, Le Maitre CL (2019) Aquaporin expression in the human and canine intervertebral disc during maturation and degeneration. JOR Spine 2: e1049. DOI: 10.1002/ jsp2.1049.

Solenov E, Watanabe H, Manley GT, Verkman AS (2004) Sevenfold-reduced osmotic water permeability in primary astrocyte cultures from AQP-4-deficient mice, measured by a fluorescence quenching method. Am J Physiol Cell Physiol 286: C426-C432.

Sowa GA, Coelho JP, Vo N V, Pacek C, Westrick E, Kang JD (2012) Cells from degenerative intervertebral discs demonstrate unfavorable responses to mechanical and inflammatory stimuli: a pilot study. Am J Phys Med Rehabil 91: 846-855.

Strotmann R, Harteneck C, Nunnenmacher K, Schultz G, Plant TD (2000) OTRPC4, a nonselective cation channel that confers sensitivity to extracellular osmolarity. Nat Cell Biol 2: 695-702.

Tanaka K, Koyama Y (2011) Endothelins decrease the expression of aquaporins and plasma membrane water permeability in cultured rat astrocytes. J Neurosci Res 89: 320-328.

Toft-Bertelsen TL, Larsen BR, Macaulay N (2018) Sensing and regulation of cell volume - we know so much and yet understand so little: TRPV4 as a sensor of volume changes but possibly without a volumeregulatory role? Channels (Austin) 12: 100-108.

Tong J, Briggs MM, McIntosh TJ (2012) Water permeability of aquaporin-4 channel depends on bilayer composition, thickness, and elasticity. Biophys J 103: 1899-1908.

Urban JPG (2002) The role of the physicochemical environment in determining disc cell behaviour. Biochem Soc Trans 30: 858-864.

Walter BA, Purmessur D, Moon A, Occhiogrosso J, Laudier DM, Hecht AC, Iatridis JC (2016) Reduced tissue osmolarity increases TRPV4 expression and pro-inflammatory cytokines in intervertebral disc cells. Eur Cell Mater 32: 123-136. 
Wehner F, Sauer H, Kinne RK (1995) Hypertonic stress increases the $\mathrm{Na}^{+}$conductance of rat hepatocytes in primary culture. J Gen Physiol 105: 507-535.

Wu L, Gao X, Brown RC, Heller S, O'Neil RG (2007) Dual role of the TRPV4 channel as a sensor of flow and osmolality in renal epithelial cells. Am J Physiol Renal Physio 293: F1699-F1713.

Wuertz K, Urban JPG, Klasen J, Ignatius A, Wilke H-J, Claes L, Neidlinger-Wilke C (2007) Influence of extracellular osmolarity and mechanical stimulation on gene expression of intervertebral disc cells. J Orthop Res 25: 1513-1522.

Yang B, Verkman AS (1997) Water and glycerol permeabilities of aquaporins 1-5 and MIP determined quantitatively by expression of epitope-tagged constructs in Xenopus oocytes. J Biol Chem 272: 16140-16146.

Zeidel ML, Ambudkar S V, Smith BL, Agre P (1992) Reconstitution of functional water channels in liposomes containing purified red cell CHIP28 protein. Biochemistry 31: 7436-7440.

Editor's note: There were no questions from reviewers for this paper, therefore there is no Discussion with Reviewers section. The Scientific Editor responsible for this paper was Sibylle Grad. 